\title{
THE GEMOLOGICAL PROPERTIES OF THE DE BEERS GEM-QUALITY SYNTHETIC DIAMONDS
}

\author{
By James E. Shigley, Emmanuel Fritsch, Carol M. Stockton, John I. Koivula,
} C. W. Fryer, Robert E. Kane, David R. Hargett, and Clayton W. Welch

\begin{abstract}
Gem-quality synthetic diamond crystals weighing up to $11 \mathrm{ct}$ have been grown in limited numbers at the De Beers Diamond Research Laboratory since the 1970s. These crystals have been produced strictly on an experimental basis and are not commercially available. Examination of a group of 14 brownish yellow, yellow, and greenish yellow synthetic diamonds reveals distinctive gemological properties: uneven color distribution, geometric graining patterns, metallic inclusions, and, in most cases, fluorescence to shortwave but not to long-wave U.V. radiation.
\end{abstract}

\section{ABOUT THE AUTHORS}

Dr. Shigley is director, Or. Fritsch is research scientist, Ms. Stockton is senior research gemologist, and Mr. Koivula is chiel gemologist in the Research Department of the Gemoiogical Institute of America, Santa Monica, CA. Mr. Fryer is director of gem identilication, Mr. Kane is senior stall gemologist, Mr. Hargett is supervisor ol gem identilication, and Mr. Welch is staff gemologist at the GIA Gem Trade Laboratory, Inc., Santa Monica, Los Angeles, and New York.

Acknowledgments: The authors thank Dr. R. J. Caveney, Dr. A. D. G. Stewart, Dr. C. M. Welbourn, and other De Beers representatives for their cooperation. Microprobe analyses were perlormed by Mr. P. Hlava of Sandia National Laboratories for U.S. DOE Contract DE-AC04-76DP00789. Unless otherwise indicated, photomicrographs are by J.l. Koivula. The article benefited from suggestions by Dr. G. Rossman, Dr. H. O. A. Meyer, Mr. R. Crowningshield, Mr. R. T. Liddicoal, Dr. D. V. Manson, and staff gemologisls of the GlA Gem Trade Laboratory, Inc.

(c) 1988 Gemological Institute of America
7 he GIA Research Department recently examined a 1 group of 14 gem-quality synthetic diamonds grown during the past few years at the De Beers Diamond Research Laboratory in Johannesburg, South Africa. This article describes the distinctive gemological properties of eight crystals ranging in weight from 0.40 to $5.23 \mathrm{ct}$ /figure 1) and six faceted specimens weighing from 0.27 to $0.90 \mathrm{ct}$ (figure 2). It represents the first report on these gem-quality synthetic diamonds in the gemological literature. The De Beers material is transparent, free of cleavages and fractures, and is dark brownish yellow, yellow, or light greenish yellow in color. De Beers representatives state that synthetic diamond crystals such as these have been grown at their research facility in South Africa since the I970s strictly on an experimental basis, and that none has been sold for any purpose. However, the fact that De Beers and other companies (e.g., Sumitomo Electric Industries in Japan; see Shigley et al., 1986) are able to produce synthetic diamonds of gem quality and in sizes that can be used in jewelry demonstrates that the commercial production of sizable gem-quality synthetic diamond crystals is no longer limited by technical difficulties, but rather only by production and marketing costs. At some future time, De Beers may make synthetic diamonds similar to those we examined available for certain high-technology applications.

Although De Beers representatives state that there are no plans to market this material for jewelry purposes, examination of these specimens offers us the opportunity to record the properties of a third group of synthetic diamonds suitable for use as gem material. By comparing the properties of the De Beers material with those of the General Electric and Sumitomo gem-quality synthetic diamonds (Crowningshield, 1971; Koivula and Fryer, 1984; Shigley et al., 1986), we can also document the gemological properties that are distinctive of gem-quality synthetic 
Figure 1. These eight gemquality synthetic diamond crystals $(0.40-5.23 \mathrm{ct})$ were manufactured on an experimental basis at the De Beers Diamond Research Laboratory and loaned to GIA for study. They fall into three distinct color groups: dark brownish yellow, yellow, and light greenish yellow. Photo (C) Tino Hammid.

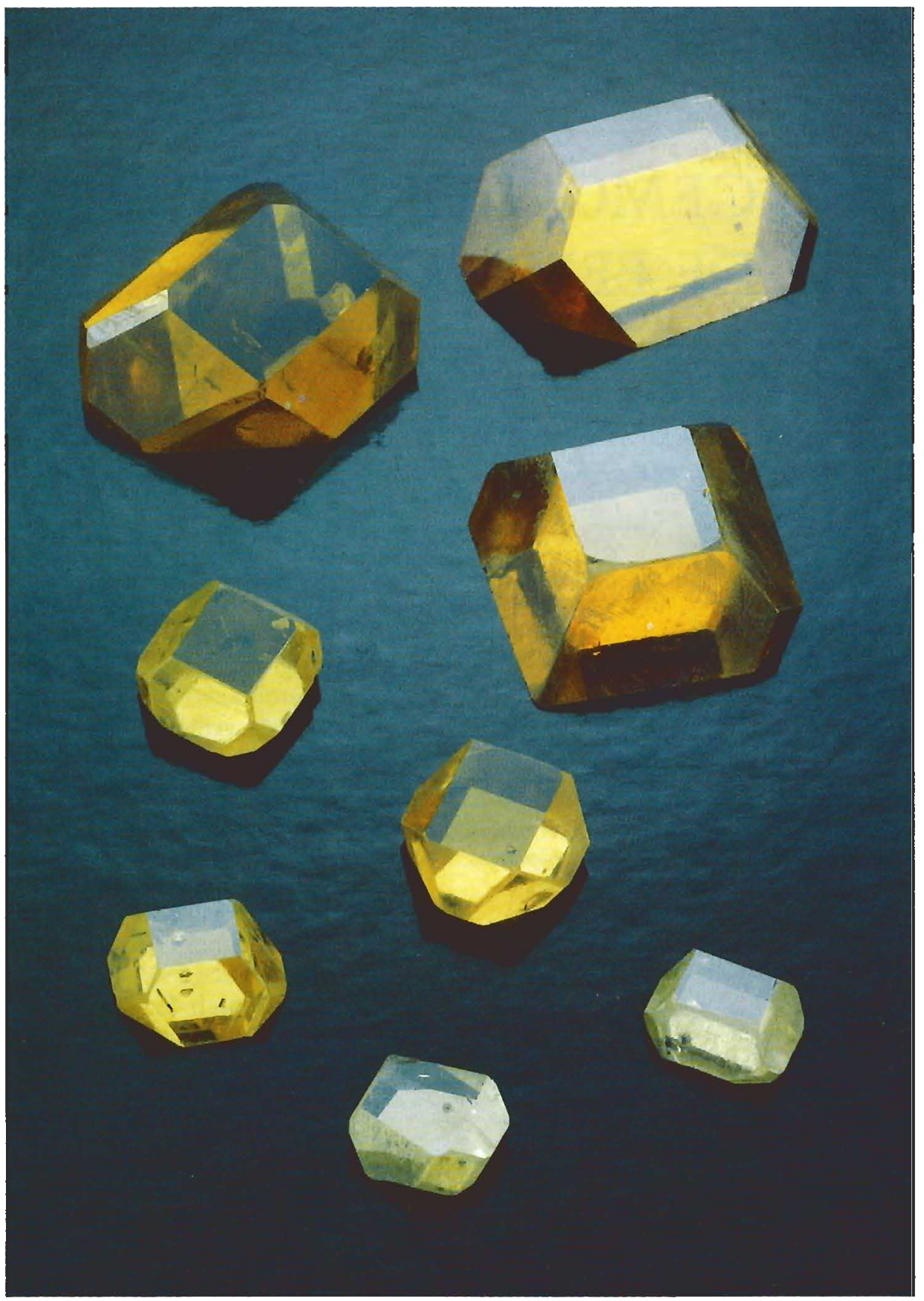

diamonds in general. In this article, where we mention features observed in the De Beers synthetic diamonds that we also noted previously in the General Electric and Sumitomo specimens, the reader should refer to the articles cited above for details on the earlier work.

\section{BACKGROUND}

In 1970, almost 15 years after creating the first industrial-quality synthetic diamonds (Bundy et al., 1955), the General Electric Company an- nounced the limited production of gem-quality synthetic diamond crystals approximately $1 \mathrm{ct}$ in size (Strong and Chrenko, 1971; Strong and Wentorf, 1972; Bundy et al., 1973). Since then, although General Electric eventually decided to discontinue work in this area, research on the growth of large, transparent synthetic diamonds for industrial applications has proceeded at other companies at an accelerating pace. The resulting new diamond synthesis technology has important gemological implications not only for the production of large 


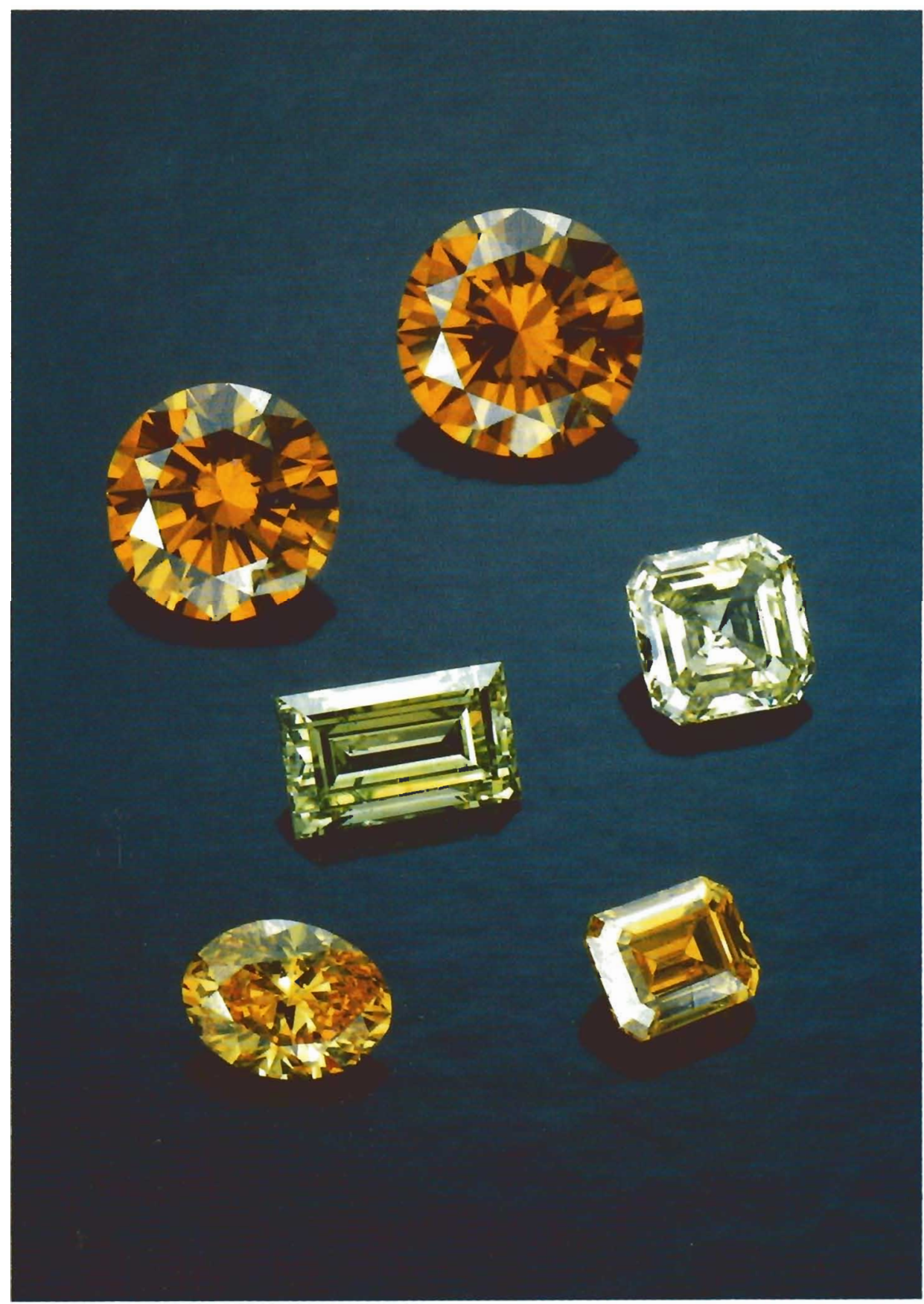

Figure 2. These six faceted De Beers synthetic diamonds $(0.27-0.90 \mathrm{ct})$ were also examined for this study. They include the largest faceted synthetic diamonds that have ever been examined at GIA. Photo (c) Tino Hammid.

synthetic diamond crystals, but also for helping to clarify scientific knowledge of the conditions of diamond formation in the earth. It may also lead to a better understanding of the causes of color in colored diamonds in instances where these causes (especially when related to irradiation or other treatment processes) are still not well known.

Until recently, production of large synthetic diamonds was restricted to a small number of crystals grown only for experimental purposes, and thus there was little chance that one of them would be encountered in the jewelry market. In 1985, however, Sumitomo Electric Industries in Japan announced the successful production of 1-2ct gem-quality yellow synthetic diamond crystals. Sumitomo researchers have perfected a method whereby transparent synthetic diamond crystals can be grown in a quantity sufficient to meet the needs of an industrial market. Because of their commercial availability, some of the Sumitomo synthetic diamonds have already been encountered in faceted form in the jewelry marketplace 


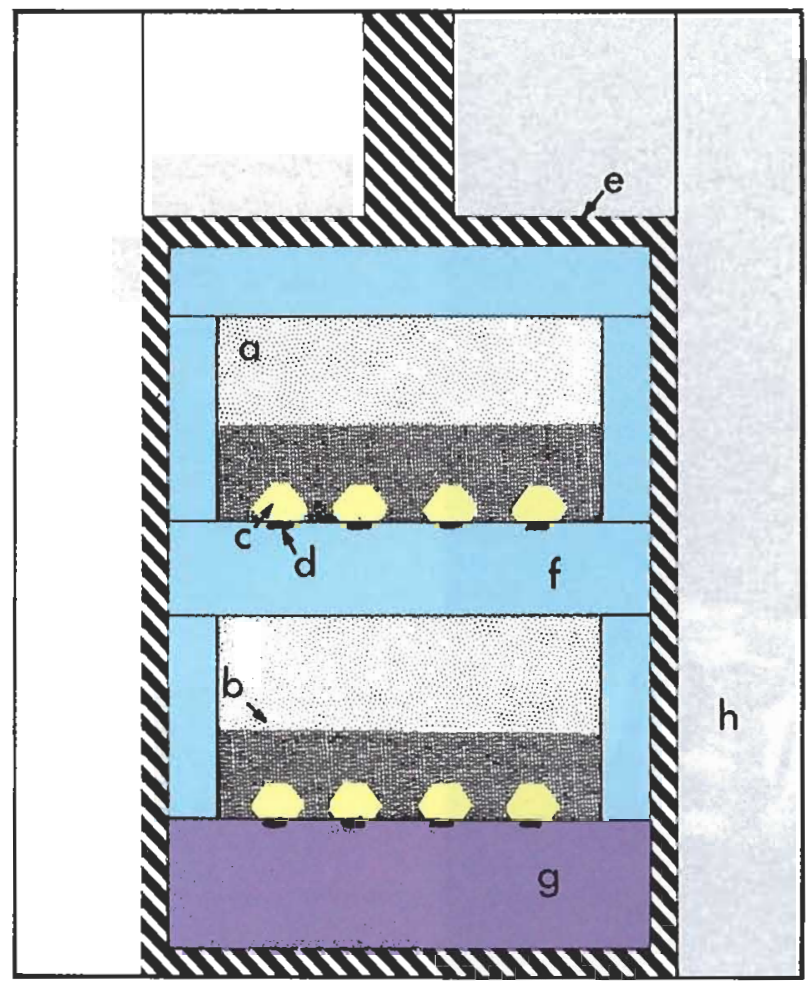

Figure 3. A reaction vessel similar to that shown in this generalized schematic drawing is used to grow single crystals of synthetic diamond by the high-pressure flux method. Temperature differences maintained within the vessel result in the carbon source material dissolving in the flux and crystallizing as single crystals of diamond on the seed crystals. In reaction vessels of this design, diamond crystals grow at several levels at the same time. Parts of the system are labeled as follows: $a=$ carbon source material (diamond powder); $b=$ metal alloy flux; $c=$ growing diamond crystal; $d=$ diamond seed crystal; $e=$ heating unit; $f=$ partition walls; $g=$ bottom wall; $h=$ insulating and pressure medium. This diagram is an idealized sketch and does not depict the actual reaction vessel used in the De Beers diamond synthesis research program. IIIustration by Peter Johnston.

(Fryer et al., 1987, p. 44). Previous reports on both the General Electric and Sumitomo gem-quality synthetic diamonds revealed features that distinguish them from natural gem diamonds (Crowningshield, 1971; Koivula and Fryer, 1984; Shigley et al., 1986). The present article demonstrates that the De Beers gem-quality synthetic diamonds also have distinctive gemological properties.
The only process that has proved economical for growing large ( $1 \mathrm{ct}$ or more) synthetic diamond crystals is a high-pressure flux method; this was first used by the General Electric scientists in the early 1970s and has since been improved /see Strong and Chrenko, 1971; Strong and Wentorf, 1972; Bundy et al., 1973; Muncke, 1979; Wedlake, 1979). The process involves crystallizing diamond from a metal alloy flux at temperatures of about 1100 to $1700^{\circ} \mathrm{C}$ and pressures of about 50 to 100 kbars, using a high-pressure reaction vessel (see figure 3). De Beers scientists used this same process to produce the diamond crystals provided for our examination.

\section{SYNTHETIC DIAMOND PRODUCTION BY DE BEERS}

The De Beers Industrial Diamond Division in Johannesburg began its own research program on diamond synthesis in the late 1950s. Within a few years, De Beers researchers developed techniques for making industrial-grade synthetic diamonds in large quantities. Since then, commercial production of synthetic industrial diamonds at De Beers facilities (as well as elsewhere) has steadily progressed to a level of production of several million carats annually. During the period 1961-1986, for example, 468 million carats of synthetic industrial diamonds were manufactured by De Beers (De Beers Consolidated Mines Ltd., 1986 Annual Reportt.

Concurrently, the De Beers Diamond Research Laboratory has also carried out extensive research on the synthesis of larger synthetic diamond crystals for possible high-technology applications. According to the laboratory director, Dr. R. J. Caveney, De Beers has been manufacturing large synthetic diamonds since the 1970 s. Dr. Caveney reports that the material loaned to us represents the various sizes, qualities, and colors of synthetic diamond crystals currently being produced.

According to Dr. Caveney, the De Beers synthetic diamond crystals are grown using a molten metal alloy flux (which acts as both a solvent and a catalyst for diamond formation) as well as a standard design reaction vessel similar to the type used to produce commercial diamond grits. Small diamond seed crystals are usually used to initiate crystal growth. Experimentation has shown that there is an optimum number and positioning of the seed crystals in the reaction vessel that will yield the largest and best-quality single crystals. 
The synthesis process involves: (1) a starting arrangement of the diamond powder source material and the molten metal alloy flux, and (2) a temperature gradient imposed within the reaction vessel. This gradient causes the diamond powder to dissolve in the metal alloy flux in the hotter source region (where the molten flux is undersaturated with respect to carbon) and the carbon to crystallize as single crystals of diamond in the cooler growth region /where the molten flux is supersaturated with respect to this element). A number of diamond crystals ranging up to 6 or $7 \mathrm{ct}$ can be grown in the reaction vessel during a single production run. Recently, De Beers researchers produced an 11.14-ct brownish yellow gem-quality synthetic diamond crystal (figure 4). The growth period for a 1 -ct crystal is reportedly about 60 hours, and for a 5 -ct crystal it is about 180 hours. The starting material, composition of the metal alloy flux, nature and positioning of the diamond seed crystals, temperature gradient, absolute temperature, and type of reaction vessel all influence the size, morphology, and yield of large diamond crystals that can be grown.

The sýnthesis process can be controlled from one production run to the next so that similar diamond crystals can be grown on a repeated basis. The color of a synthetic diamond depends on the type and amount of trapped impurities, which in turn can be influenced by adjusting the chemistry of the components of the growth system. According to Dr. Caveney, while a few pale yellow and colorless synthetic diamonds have been manufactured, currently they are not as easy to grow in high-quality single crystals as the brownish yellow, yellow, and greenish yellow crystals we examined. Blue type IIb synthetic diamond crystals are also more difficult to grow at the present time. However, De Beers is not growing diamond crystals to produce particular colors, but rather to obtain certain desired properties, such as high thermal conductivity, for specific industrial applications. Since the total number of crystals that can be grown during a particular time period is restricted by cost and by the limited amount of synthesis equipment available, De Beers representatives believe that the industrial use of their large synthetic diamonds will remain restricted to highly specialized applications.

\section{RESULTS OF TESTING}

Table 1 provides the color, weight, dimensions, and

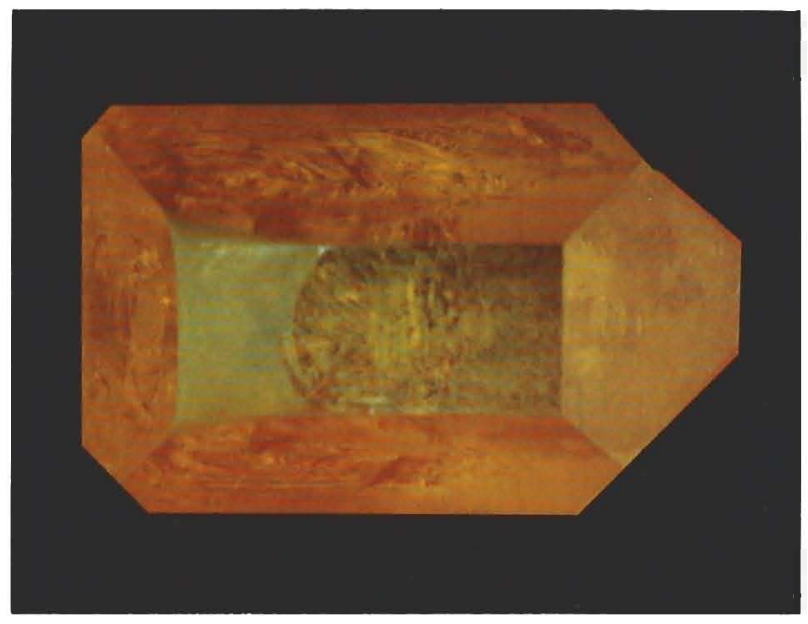

Figure 4. This 11.14-ct synthetic diamond crystal is the largest gem-quality synthetic diamond crystal grown thus far at the De Beers Diamond Research Laboratory in Johannesburg. The crystal (17 $\mathrm{mm}$ in its longest dimension) is an elongate octahedron modified by cube faces. Photograph courtesy of Dr. R. J. Caveney.

physical description of the De Beers synthetic diamonds we examined. The eight crystals (figure 1) were reported to be in the same condition as when grown except for cleaning to remove pieces of flux and other surface contaminants. To facilitate viewing of internal features, the upper and lower surfaces of the crystals had also been polished. The amount of material removed by polishing was reportedly limited, but the specimens as supplied to us actually represent only portions of complete crystals (although they are herein referred to as crystals|. In the description of crystal morphology and surface features that follows, the characteristics given apply to all of the crystals except as indicated. No obvious differences in shape or surface features were noted between crystals of the three colors; however, the brownish yellow crystals are the largest while those that are greenish yellow are the smallest (which may just be coincidental).

The six faceted synthetic diamonds we examined (figure 2) were cut in standard brilliant and step cuts. Dr. Caveney reported that no problems or unusual behavior were encountered during the faceting of these synthetic diamonds. Table 2 summarizes the more distinctive gemological properties documented by conventional testing methods that we found in these six faceted synthetic diamonds. 
Morphology of the Crystals. The synthetic diamond crystals supplied by De Beers are octahedrons modified by cube, dodecahedral, and other faces /reported to be trapezohedral faces-see Woods and Lang, 1975-and described herein as such) in order of decreasing surface area and frequency of occurrence (figures 1 and 5). We noted the same kinds of crystal faces on the General Electric and Sumitomo synthetic diamond crystals. Some of the De Beers crystals have a square shape, but the majority are rectangular (figure 4). These crystals have relatively sharp edges and corners as well as predominantly flat faces. In contrast, although many natural gem diamond crystals also take the form of an octahedron, they often have rounded edges and corners, convexappearing surfaces, a more complex arrangement of crystal faces, and can be less symmetrical in shape. Our observations suggest that the De Beers crystals have a simpler land thus more recogniz- able) crystal form than do many natural diamonds This ideal shape results both from the controlled growth environment and from the fact that diamond crystals produced in the laboratory do not undergo the complex history of growth and dissolution stages that is encountered during the formation of many natural diamond crystals (Strong and Chrenko, 1971; Strong and Wentorf, 1972; Muncke, 1979|.

Surface Features of the Crystals. A number of researchers have observed several important differences between natural and synthetic diamonds in surface features or markings on the crystal faces; they have attributed these differences to the respective conditions of crystal growth (see, e.g., Tolansky and Sunagawa, 1959; Bovenkerk, 1960; Tolansky, 1961, I962; Patel and Ramanathan, I963; Patel and Ramachandran, 1968; Orlov, 1977; Moore, 1979). We found the crystal faces of the De

TABLE 1. Data on the De Beers gem-quality synthetic diamonds examined for this study.

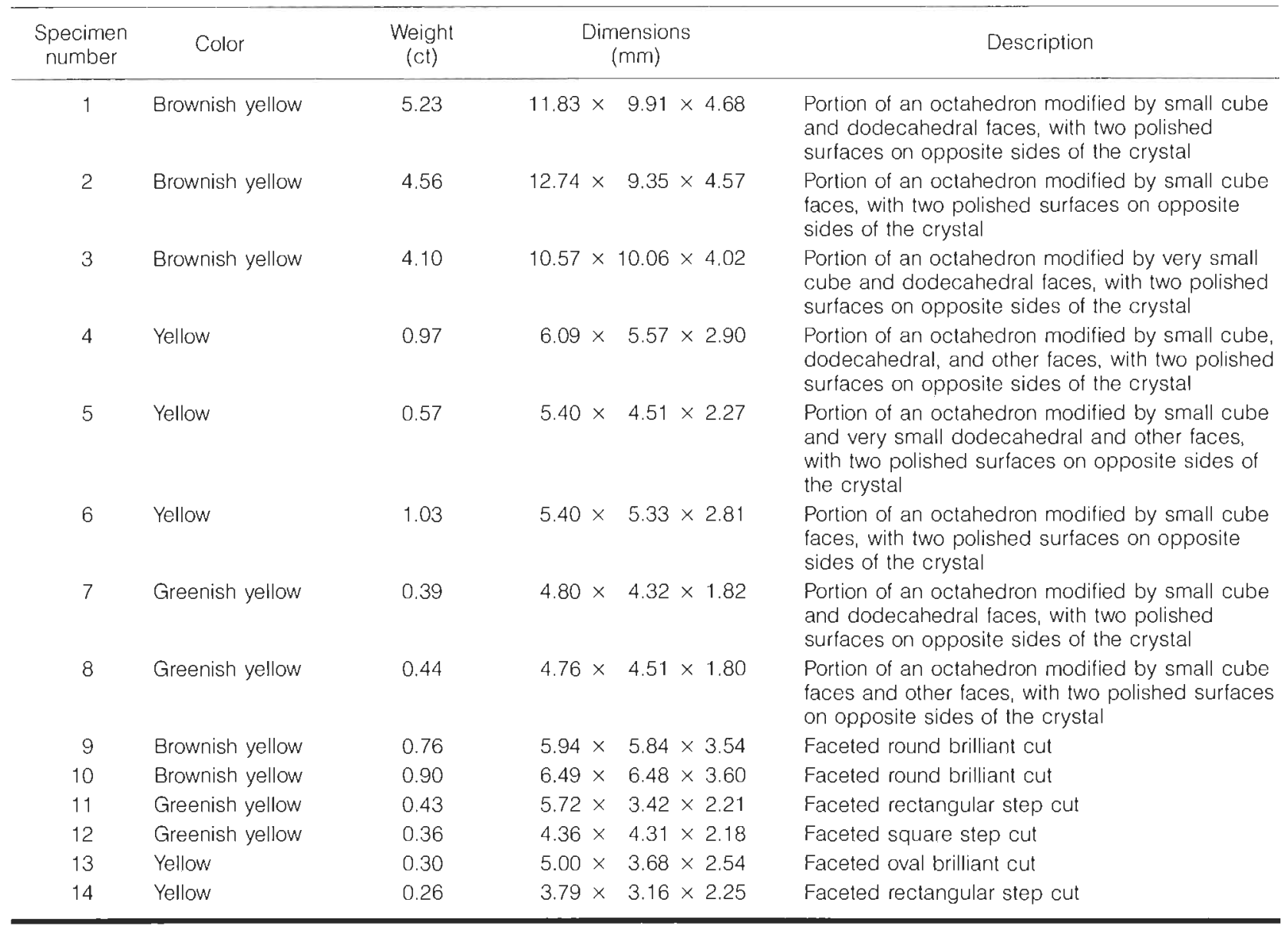


TABLE 2. Distinctive gemological properties of the brownish yellow, yellow, and greenish yellow faceted De Beers synthetic diamonds ${ }^{a}$

\begin{tabular}{|c|c|c|c|}
\hline Property & Brownish yellow & Yellow & Greenish yellow \\
\hline \multicolumn{4}{|l|}{ Ultraviolet fluorescenceb } \\
\hline Long wavec & None & None & None \\
\hline Short wave & $\begin{array}{l}\text { Moderate to strong intensity; } \\
\text { yellow or greenish yellow; } \\
\text { strongly zoned with } \\
\text { nonfluorescing areas }\end{array}$ & None & $\begin{array}{l}\text { Weak intensity; yellow; } \\
\text { zoned }\end{array}$ \\
\hline $\begin{array}{l}\text { Phosphorescence to } \\
\text { ultraviolet radiation }\end{array}$ & None & None & $\begin{array}{l}\text { Weak intensity; yellow; } \\
\text { duration of } 10 \text { seconds } \\
\text { or more }\end{array}$ \\
\hline $\begin{array}{l}\text { Visible-range absorption } \\
\text { spectrum }\end{array}$ & No sharp bands & No sharp bands & No sharp bands \\
\hline Color distribution & $\begin{array}{l}\text { Distinct color zoning; aligned } \\
\text { with pattern of internal graining }\end{array}$ & $\begin{array}{l}\text { Distinct color zoning; aligned } \\
\text { with pattern of internal graining }\end{array}$ & $\begin{array}{l}\text { Subtle to distinct color } \\
\text { zoning }\end{array}$ \\
\hline \multicolumn{4}{|l|}{ Graining } \\
\hline Internal & $\begin{array}{l}\text { Often obvious; sometimes } \\
\text { colored; "hourglass" pattern of } \\
\text { intersecting lines }\end{array}$ & $\begin{array}{l}\text { Often obvious; sometimes } \\
\text { colored; "hourglass" pattern of } \\
\text { intersecting lines }\end{array}$ & $\begin{array}{l}\text { Rarely visible; pattern } \\
\text { of intersecting lines }\end{array}$ \\
\hline Surface (on table) & Octagonal "stopsign" pattern & Faint lines & Faint lines \\
\hline Inclusions & $\begin{array}{l}\text { Dense clouds of tiny, white-appearing } \\
\text { pinpoints; larger metallic inclusions }\end{array}$ & $\begin{array}{l}\text { Clouds of tiny, white- } \\
\text { appearing pinpoints; } \\
\text { larger metallic inclusions }\end{array}$ & $\begin{array}{l}\text { Isolated, tiny, white- } \\
\text { appearing pinpoints; } \\
\text { larger metallic inclusions }\end{array}$ \\
\hline Crystal surface features ${ }^{d}$ & \multicolumn{3}{|c|}{$\begin{array}{l}\text { Dendritic patterns; triangular pyramids; granular or irregular surfaces possible on faceted DeBeers } \\
\text { synthetics }\end{array}$} \\
\hline
\end{tabular}

aSome gemological properties noled as being prominent in the synthelic diamond crystals are less evident or are complelely absent in the faceled specimens. Thus, the information provided in this table is based on observations made only on the vaceted synthetic diamonds.

oThe perceived intensily and color of the uitraviolet fluorescence of a gemstone can be influenced by the observation conditions'type and age of the U.V lamp, condition of the short-wave fitter of the lamp, viewing arrangement, brightness of the room, elc.).

A weak orangy yellow or yellow fluorescence was observed in some of these samples (especially in the greenish yellow ones) with a more iniense long-wave U.V. lamp (such as a GIA GEM Instrumen's Model No. 745 unit).

a Crystal surface lealures such as these could be retained at places along the girdle of a faceted stone where there are unpolished remnants of the original crystal faces.

Beers synthetic diamonds to display some distinctive surface features that could be retained on unpolished sections of the girdle of a faceted stone, and thus could be of use gemologically.

Specifically, the octahedral crystal faces on the De Beers synthetic diamonds have the smoothest surfaces. When observed with magnification, these relatively smooth faces can have an irregular, hillocky appearance with slightly raised or lowered areas that form a polygonal arrangement. We noted several distinctive features on these octahedral faces.

Gemologists generally use the term trigon to describe any triangular-shaped marking on an octahedral face of a natural diamond crystal. These trigons are sometimes seen on unpolished portions (referred to as "naturals") at the girdle of a faceted natural diamond, and they are used as a confirmation that the faceted stone is in fact a diamond. Such triangular-shaped features can actually occur either slightly above or slightly below the surrounding surface. Trigons correctly refer only to small triangular depressions on an octahedral face of a diamond (Webster, 1970). If they project above the surface, these features should correctly be described as triangular pyramids (Patel and Ramanathan, 1963). We observed triangular pyramids of various sizes on the octahedral faces of many of the De Beers synthetic diamond crystals (figure 6). However, we found no trigons, although other researchers have reported seeing them on synthetic diamond crystals in rare instances (Bovenkerk, 1960; Tolansky, 1962). The presence of triangular pyramids and trigons on the octahedral crystal faces of both synthetic and natural diamond crystals indicates that these features cannot be used as an identification criterion.

Other surface features occur on the octahedral faces of most of the De Beers synthetic diamond crystals. These include: (1) numerous tiny pits on the triangular pyramids and other elevated areas of a face that may have resulted from etching when the crystal was cleaned of flux and surface contaminants; (2) a slightly raised edge around part of a 
face; and (3) slightly elevated dendritic markings covering portions of a face (figure 7), which is one of the most characteristic surface features seen on synthetic diamond crystals (Tolansky and Sunagawa, 1959; Tolansky, 1962; Shigley et al., 1986).

The cube faces are smaller than the octahedral faces, but they were observed on all of the De Beers synthetic diamond crystals we studied. In contrast, cube faces are not commonly seen on natural gem diamond crystals, and when they do occur, their surface texture is quite rough and pitted (Tolansky, 1961, 1962). On the De Beers crystals, the cube faces are planar but they display an irregular, polygonal, or granular appearance over their entire area (figure 8). We also observed a few square pyramids as well as some dendritic surface markings on these faces.

The dodecahedral faces are small, elongate, and have rough surfaces. They commonly exhibit striations oriented parallel to the long direction of the face and often running its entire length. These

Figure 5. In this drawing of an idealized synthetic diamond crystal, the crystal is an octahedron modified by other smaller faces. The crystal faces are identified as follows: $o=$ octahedral; $a=$ cube; $d=$ dodecahedral; $n=$ trapezohedral. On an actual crystal like the ones we examined, the number, arrangement, and relative sizes of the crystal faces may differ slightly from what is depicted here. Illustration by Peter Johnston.

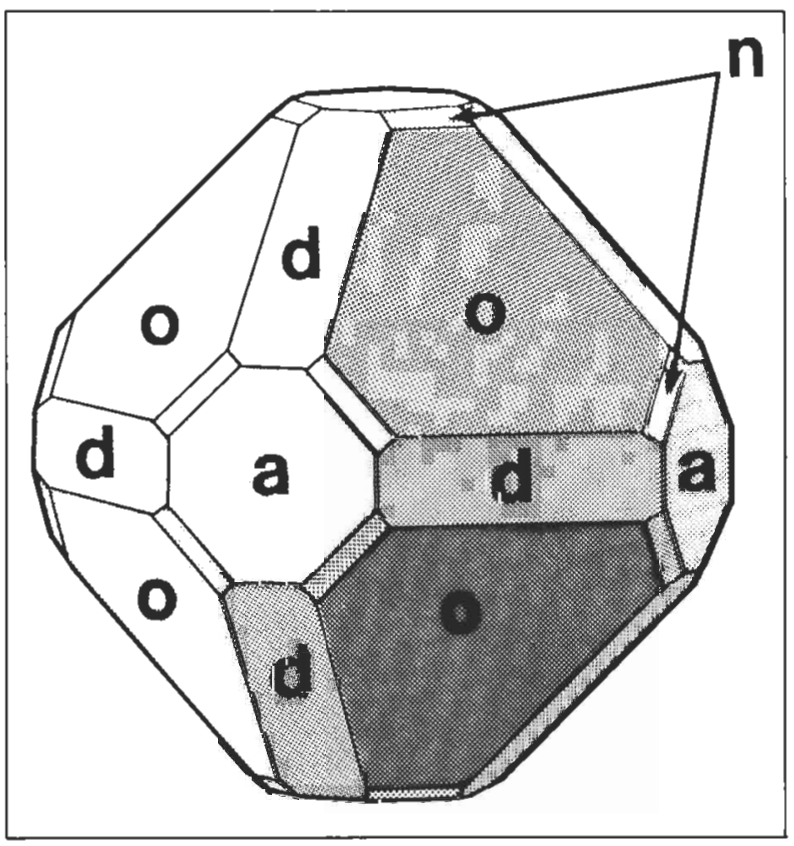

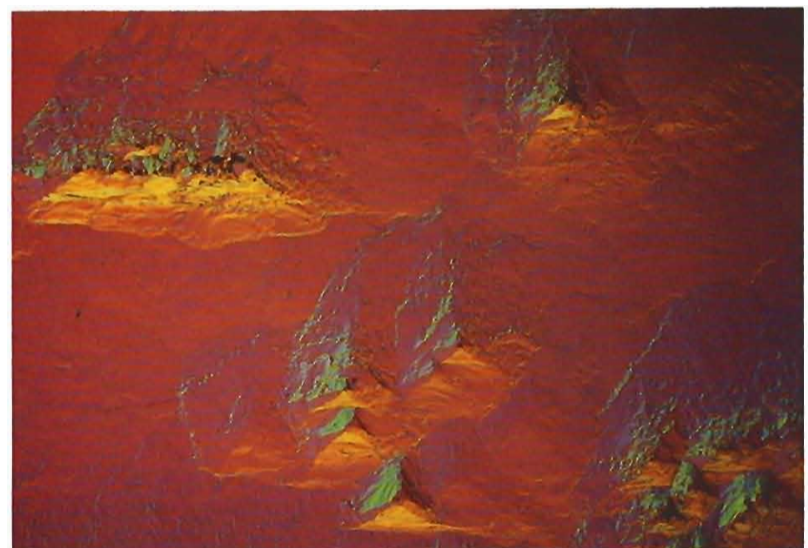

Figure 6. Triangular pyramids were observed on the octahedral faces of many of the De Beers synthetic diamond crystals. This photomicrograph was taken by the Nomarski interference contrast method, which emphasizes slight differences in relative surface elevation by the use of color. The triangular features shown here are all pyramids that project above the surrounding surface (and therefore should not be called trigons). Magnified $60 \times$.

faces are unequally developed in size, and do not appear at all on some crystals.

The fourth type of crystal face (believed to be trapezohedral) almost always occupies the smallest surface area on the De Beers synthetic diamond crystals. These faces have the roughest appearance, can also be striated, and, like the dodecahedral faces, do not appear on all crystals.

Our observations on the De Beers crystals confirmed many of the surface features (e.g., cube faces, dendritic markings) that have been found on other synthetic diamonds, such as the Sumitomo material. Whether these features on the De Beers crystals are the result of growth processes or of partial dissolution is unclear. However, the absence of trigons combined with the fact that most surface features (such as the triangular pyramids) project above the surface suggests that these features result from growth processes. Nevertheless, the dendritic markings and some of the other surface features are distinctive of these and other synthetic diamond crystals, and they have not been observed on natural diamond crystals. Therefore, these features can provide useful identification guidelines.

For the most part, the girdles of the faceted De Beers synthetic diamonds we examined are either 


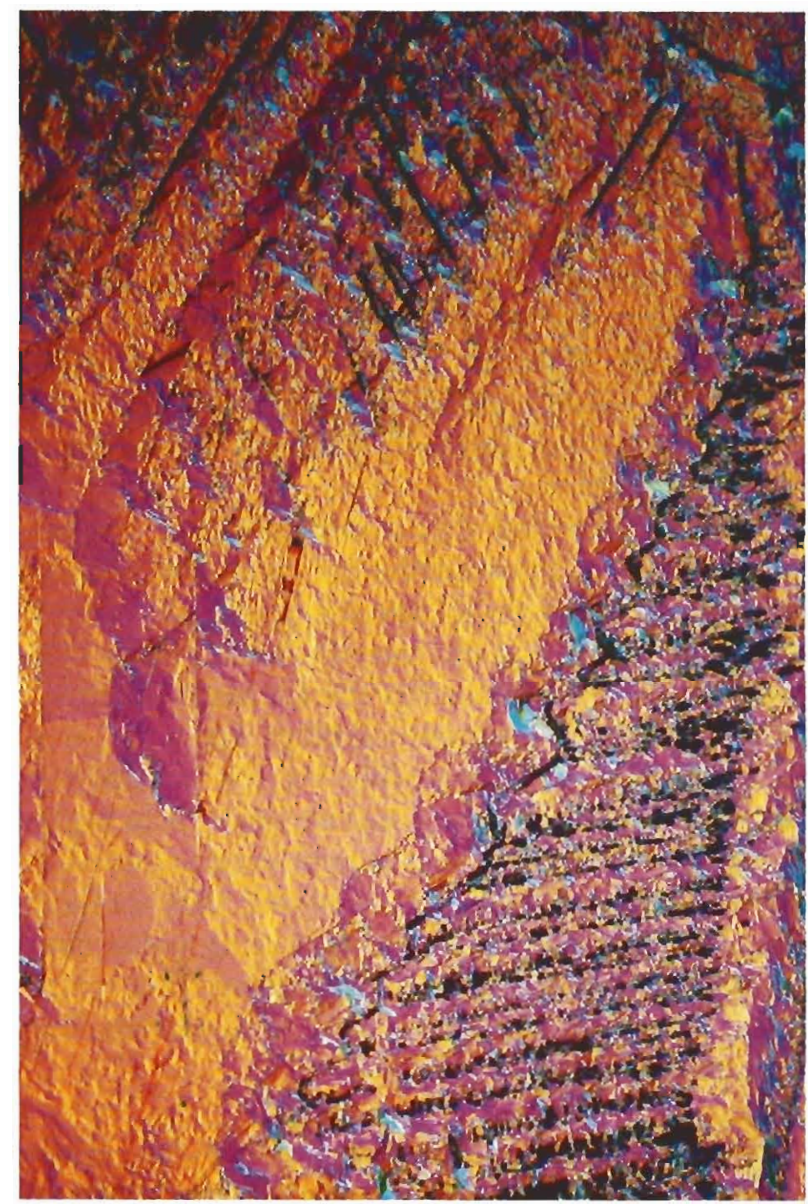

Figure 7. Dendritic surface markings on an octahedral face, shown here on a De Beers specimen, are one of the most characteristic features of a synthetic diamond crystal. Nomarski interference contrast; magnified $40 \times$

polished or have a bruted appearance. We did find several small unpolished areas that display the same rough, dendritic, striated, or irregular surface features that we observed on the synthetic diamond crystals. If observed on a cut stone, such features could be useful for identification purposes.

Color. Five of the 14 De Beers synthetic diamonds examined are dark brownish yellow; this group includes the largest crystals and cut stones. Five of the synthetic diamonds are yellow, while the last four are light greenish yellow. We found the color in most of the synthetic diamonds to be unevenly distributed (figure 9) with respect to either hue or intensity. This color zonation can vary from rather subtle to quite pronounced. The boundaries be-

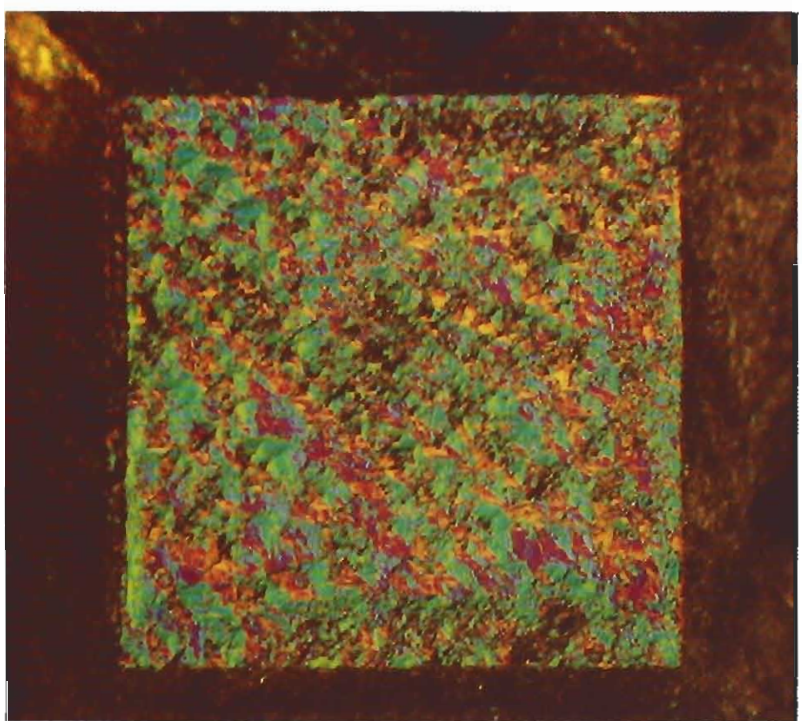

Figure 8. The cube faces of the De Beers synthetic diamond crystals examined all have an irregular, granular appearance. Nomarski interference contrast; magnified $45 \times$.

tween areas of slightly differing color may be sharp or gradual, and they are sometimes marked by grain planes that are themselves colored. Although uneven coloration was also noted in the General Electric and Sumitomo synthetic diamonds, the patterns of color zoning in these three instances do not correspond.

Figure 9. In this faceted yellow De Beers synthetic diamond, the unevenness of the color is quite pronounced, with both yellow and colorless areas forming a geometric arrangement. Color zonation such as this is rarely if ever seen in a faceted natural diamond of similar color. Magnified $10 \times$

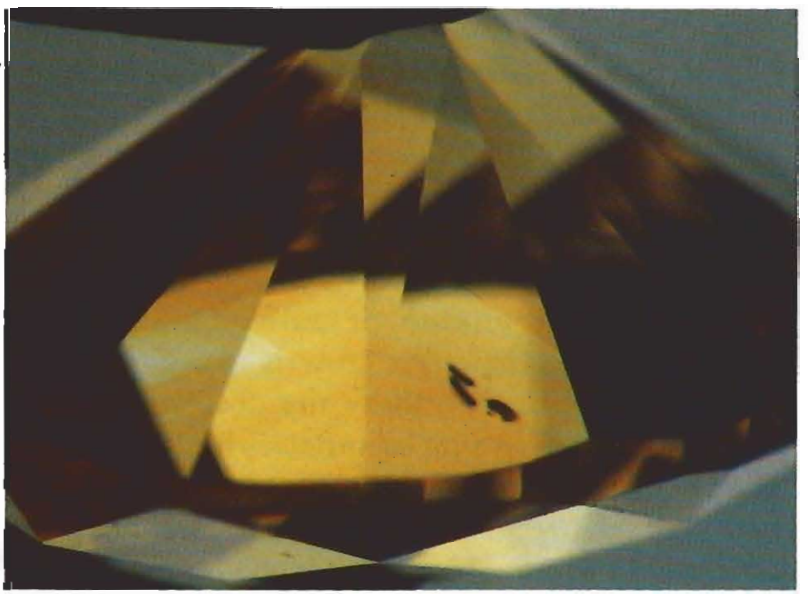


We found that this color distribution in the De Beers synthetic diamonds, although uneven, usually forms a regular geometric pattern. The pattern of color zoning can be correlated not only with the outer shape of the crystal but also, more importantly, with the internal growth structure of the diamond. An explanation of this relationship requires some brief remarks on the different mechanisms of diamond crystal growth in the earth versus those in the laboratory.

It is possible to find natural diamond crystals that are virtually free of internal structural irregularities. This is due to the fact that natural diamond crystals grow over extended periods of time in the earth by the addition of layers of material mostly parallel to the surfaces of an octahedron. This octahedral-type growth /also described as "faceted" growth because of its very planar character) produces the prominent octahedral faces that are characteristically seen on many natural diamond crystals.

In the laboratory, diamond formation takes place in just a matter of days. This rapid crystallization leads to the growth of crystals by the addition of material parallel not only to octahedral faces but also to cube, dodecahedral, and possibly other crystal faces as well (see Lang, 1979, for details). As a result, in a large laboratory-grown diamond there invariably seem to exist different internal regions, or sectors, of the crystal. Within each sector, growth parallel to a particular crystal face loctahedral, cube, or other) predominates during crystal formation. These various growth sectors can differ from one another in impurity content, in the number and kinds of structural defects, and in physical properties such as polishing hardness. Such differences provide a means of differentiating between growth sectors. As growth proceeds, the boundary zones between adjacent sectors also become the sites where impurities and defects are likely to become concentrated.

In the brownish yellow or yellow De Beers synthetic diamond crystals we examined, these growth sectors can be recognized by marked variations in their color and ultraviolet fluorescence, by the occurrence of prominent grain planes (parallel to cube faces) in the cubic growth sectors that are absent in the others, and by the occasional presence of inclusions along boundaries between some sectors. Growth sectors are also present in the greenish yellow crystals but are less easy to distinguish. Figure 10 is an idealized drawing of the arrangement of octahedral and cubic growth sectors in a brownish yellow synthetic diamond crystal. These internal growth sectors may not be as equally well developed or as centrally positioned in some crystals as is depicted here, and they may not be quite as obvious to the eye. For all of the crystals, the grow th sectors were more casily visible when the stones were immersed in methylene iodide. Even in some of the faceted specimens, the growth sectors are apparent (the color zoning in the cut stone in figure 9 results from sector growth).

We suggest that this arrangement of distinct grow th sectors, as evidenced by variations in color zoning and other gemological properties, is one of the most prominent characteristics of yellow synthetic diamond crystals like the De Beers material. Although not fully appreciated at the time, this sector growth is responsible for the distinctive color zoning and graining that we noted as being so prominent in the Sumitomo synthetic yellow diamonds. We should caution, however, that we have observed somewhat similar-appearing color zoning/that is perhaps due to causes other than sector growth) in faceted natural yellow diamonds, but only on very rare occasions.

Spectroscopy. The vast majority of natural yellow diamonds are classified as type Ia (for details of diamond classification by type, see Shigley et al., 1986), and they usually display one or more sharp absorption bands of varying intensity in the violet and blue portions of their visible-range spectrum (including those known as the "Cape" series of bands). When viewed with a hand spectroscope, the spectra of the De Beers synthetic diamonds exhibit no sharp bands in the visible range; there is only a gradually increasing absorption toward the ultraviolet. This was also the case for the General Electric and Sumitomo synthetic yellow diamonds. Visible-range absorption spectra of this kind are characteristic of type Ib diamonds. The spectrophotometer graphs reproduced in figure 11 confirm these observations, and also help to illustrate the differences in color among the De Beers synthetic diamonds. For the brownish yellow and yellow specimens, the spectral curves begin to rise markedly at about $560 \mathrm{~nm}$. Both kinds of synthetic diamond absorb violet, blue, and some green light and transmit the remaining portions of the spectrum, which gives rise to their yellow color.

The spectra of the four light greenish yellow 


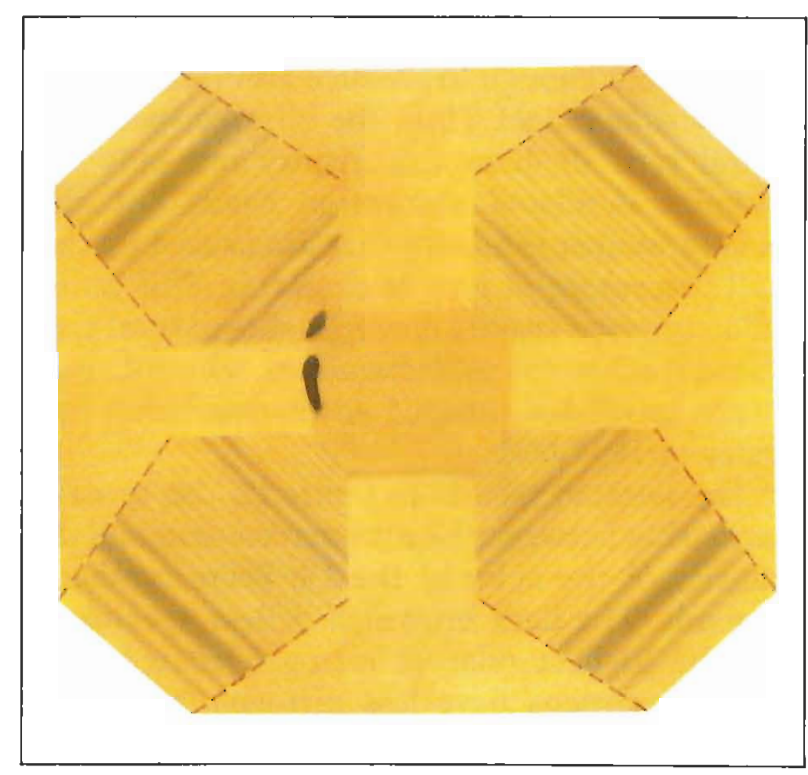

Figure 10. This idealized drawing of the internal structure of one of the brownish yellow synthetic diamond crystals (viewed from a direction perpendicular to a cube crystal face) illustrates the prominent internal sector growth and the resulting distinctive graining patterns and color.zoning. These features have been accentuated here for clarity and to emphasize their spatial relationship to each other. Octahedral and cubic growth sectors of similar size are arranged in cross-shaped patterns around the central core of the crystal (which is also a cubic growth sector). Crystal growth proceeded outward from the center in these sectors. Within the cubic sectors, crystal growth was accompanied by the development of colored graining. Graining is absent in the adjacent octahedral sectors. Along the edge of the central zone there are several crystallographically oriented metallic inclusions as well as additional grain lines that mark this boundary. Illustration by Robin Teraoka.

synthetic diamonds are slightly different. Specifically, these synthetic diamonds absorb less light in the violet and blue. Their spectral curve is shifted, and begins to rise at about $520 \mathrm{~nm}$, and it also exhibits an increase in absorption above $620 \mathrm{~nm}$ that is slight but nonetheless significant in modifying the otherwise yellow color of this material. The absorption of violet and blue, as well as some orange and red, gives rise to a transmission window in the green-yellow region between 520 and $620 \mathrm{~nm}$ and thus to the greenish yellow body color.

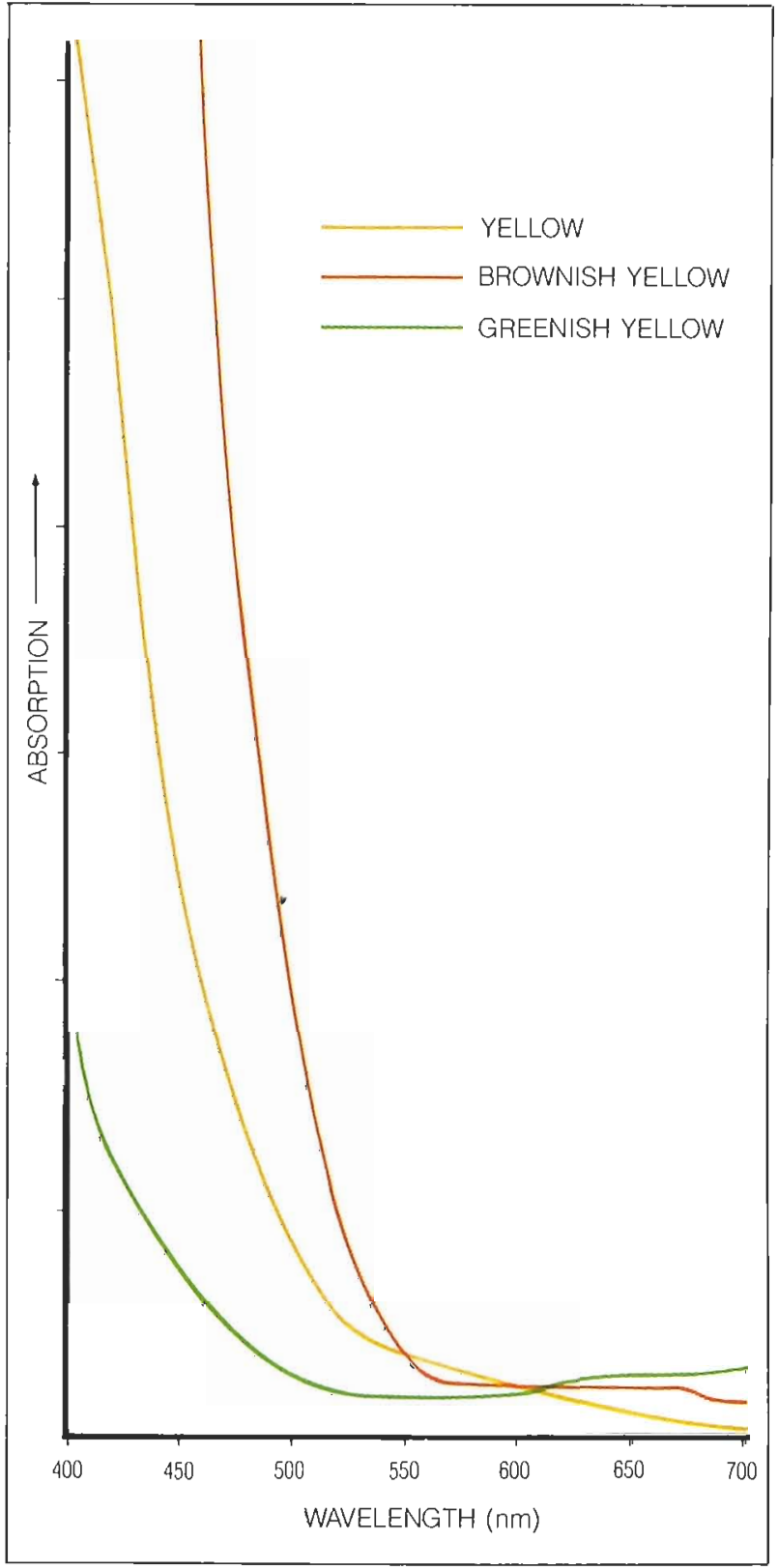

Figure 11. The visible-range absorption spectra of the three colors of De Beers synthetic diamonds exhibit no sharp absorption bands but only a gradually increasing absorption toward the violet. The spectrum of the greenish yellow material also exhibits a slight increase in absorption toward the red. The spectra were recorded at room temperature with a PyeUnicam 8800 UV-VIS spectrophotometer from crystals that have two nearly parallel, polished sides. Absorption values along each curve were normalized for a unit path length to permit direct comparison of the spectra. Illustration by Peter Johnston. 
The greenish yellow color of synthetic diamonds has been the subject of other scientific studies. For instance, Collins and Spear (1982) investigated some General Electric synthetic green diamonds grown from a nickel flux. They indicated that the green color results from absorption at the violet end of the visible-range spectrum (due to nitrogen) in conjunction with a broad-band absorption centered in the near-infrared (at about $1.4 \mathrm{eV}$ ) and extending into the red portion of the visible spectrum (about $2.0 \mathrm{eV}$ ). Wedlake (1979) noted that the green color in some other synthetic diamonds is concentrated near nickel inclusions. Orlov (1977, p. 127) described experimental work in which natural diamonds had been colored green by the diffusion of nickel into their surfaces. On the basis of this circumstantial evidence, Collins and Spear suggest that the $1.4 \mathrm{eV}$ broad-band absorption extending from the near-infrared into the visible range that contributes to the green color of synthetic diamonds is associated with nickel that becomes incorporated in the diamond crystal structure during crystal growth in the laboratory. They also attribute the presence of two groups of sharp absorption bands in the visible range at approximately 659 and $494 \mathrm{~nm}$ in this material to nickel. The fact that the De Beers synthetic diamonds display metallic inclusions that contain nickel (see later discussion) may indicate that the greenish yellow color of some of the De Beers material is also the result of trace amounts of this element.

Infrared Spectra. The infrared spectrum can be used to classify a diamond according to its type. Figure 12 shows the infrared spectra obtained with a Fourier Transform infrared (FTIR) spectrometer for each of the three colors of De Beers synthetic diamonds that we examined; these spectra indicate that the synthetic diamonds have nitrogen impurities in the form of type Ib. The yellow color of type Ib diamonds is caused by nitrogen that is dispersed as single atoms substituting for carbon atoms in the diamond crystal structure /Chrenko et al., 1971; Clark et al., 1979|. Most natural yellow gem diamonds are type Ia, and they contain nitrogen in the form of small clusters of neighboring atoms. Natural type Ib yellow gem diamonds are rare. As mentioned above, such diamonds lack sharp absorption bands in their visible-range spectra. However, natural type Ib diamonds with dispersed nitrogen atoms also invariably contain a small amount of nitrogen atoms in an aggregated form (but not enough to produce absorption bands in the visible rangel. Thus, the infrared spectra of natural type Ib diamonds display not only the dominant Ib-related absorption bands but also bands of weaker intensity that are caused by this small percentage of type Ia character. This difference in infrared spectra distinguishes natural type Ib from synthetic type Ib diamonds, which display no type Ia-related infrared absorption bands |see Shigley et al., 1986).

The infrared spectra in figure 12 also reveal a relationship between the nitrogen content and the intensity of the color of the De Beers synthetic diamonds. The dark brownish yellow specimens have the highest relative nitrogen content, the yellow specimens have less nitrogen, while the light greenish yellow specimens contain the least nitrogen.

The infrared spectra of the De Beers synthetic diamonds exhibit an additional interesting feature. As noted above, the visible-range absorption spectrum of the greenish yellow specimens is somewhat different from that of the other two colors. Microscope examination of one of the greenish yellow faceted synthetic diamonds revealed a color zonation in which most of the internal growth sectors are yellow, a few are colorless, and some appear distinctly green. In addition to the expected type Ib absorption, the infrared spectrum of a green sector of this specimen (figure 13) displays weak bands that look very similar to infrared features characteristic of type IIb natural diamonds, which are electrically conductive because of the presence of boron instead of nitrogen and are usually blue or gray. The type IIb-like infrared absorption features that we observed in this stone and which would not be expected in the infrared spectrum of a nitrogencontaining type Ia or type Ib diamond) are located at $4090,2930,2800$, and $2450 \mathrm{~cm}^{-1}$. Whether these bands are associated with boron or with some other defect center is currently under study.

In the previous section we briefly described a thesis that proposes that the greenish color of some of the De Beers synthetic diamonds could be due to the presence of traces of nickel in the diamond crystal structure (see Collins and Spear, 1982). On the other hand, if boron or some other defect center that gives rise to type IIb-like bands in the infrared spectrum were present in the green sectors of the greenish yellow De Beers synthetic diamonds, this 


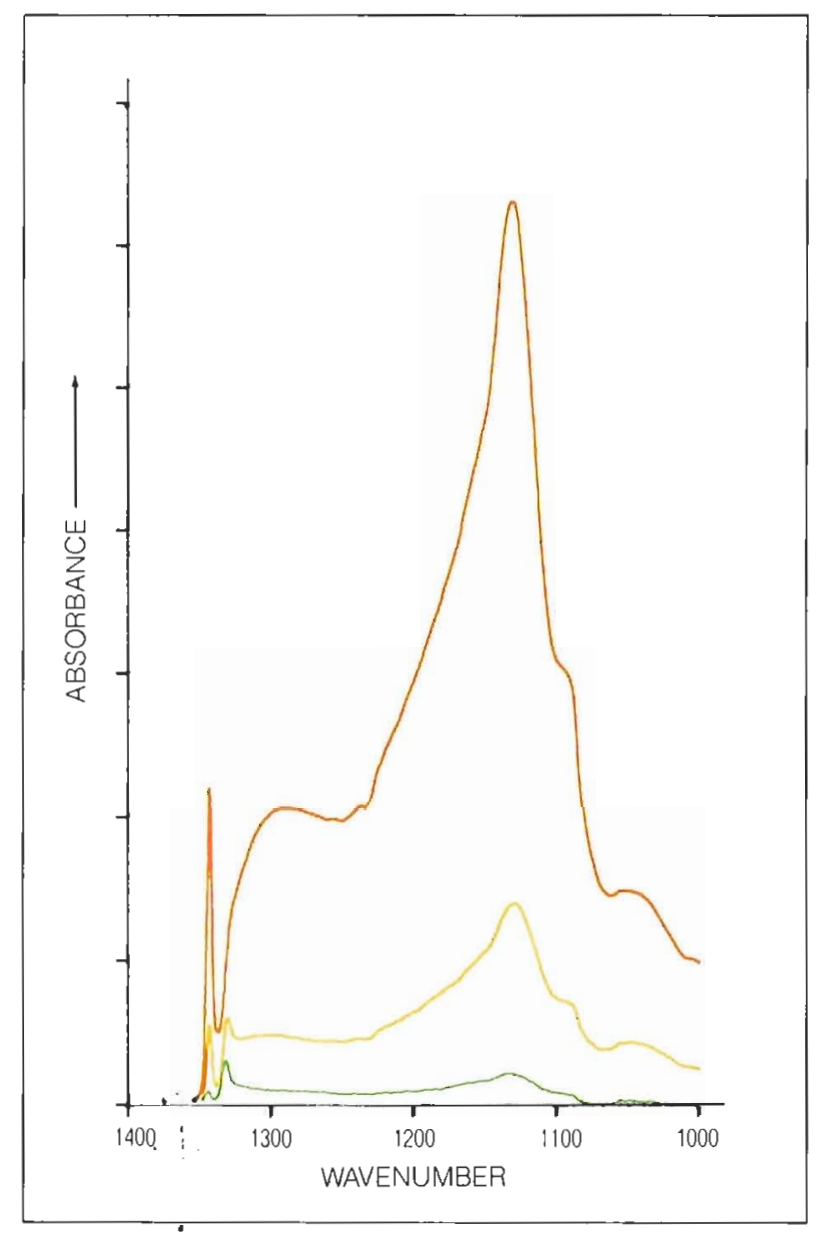

Figure 12. Features in the $1000-1400 \mathrm{~cm}^{-1}$ portion of the infrared spectra of the dark brownish yellow (top), yellow (middle), and light greenish yellow (bottom) De Beers synthetic diamonds indicate that they are all principally type $I b$ with no type Ia character. The spectra of natural type Ib diamonds invariably contain not only the dominant type Ib-related infrared bands, but weaker type Ia-related bands as well. The spectra shown here also reveal that the De Beers synthetic diamonds have different relative contents of nitrogen, ranging from relatively high in the dark brownish yellow, lower in the yellow, and lowest in the light greenish yellow specimens. The spectra were recorded with a Nicolet $605 \mathrm{X}$ FTIR spectrometer system. Absorption values along each curve were normalized to a unit path length to permit direct comparison of the spectra.

might account for some of our observations on the properties of these specimens.

If both dispersed nitrogen (type Ib) and dispersed boron (type IIb) coexisted in neighboring sites in the crystal lattice of a diamond, they could

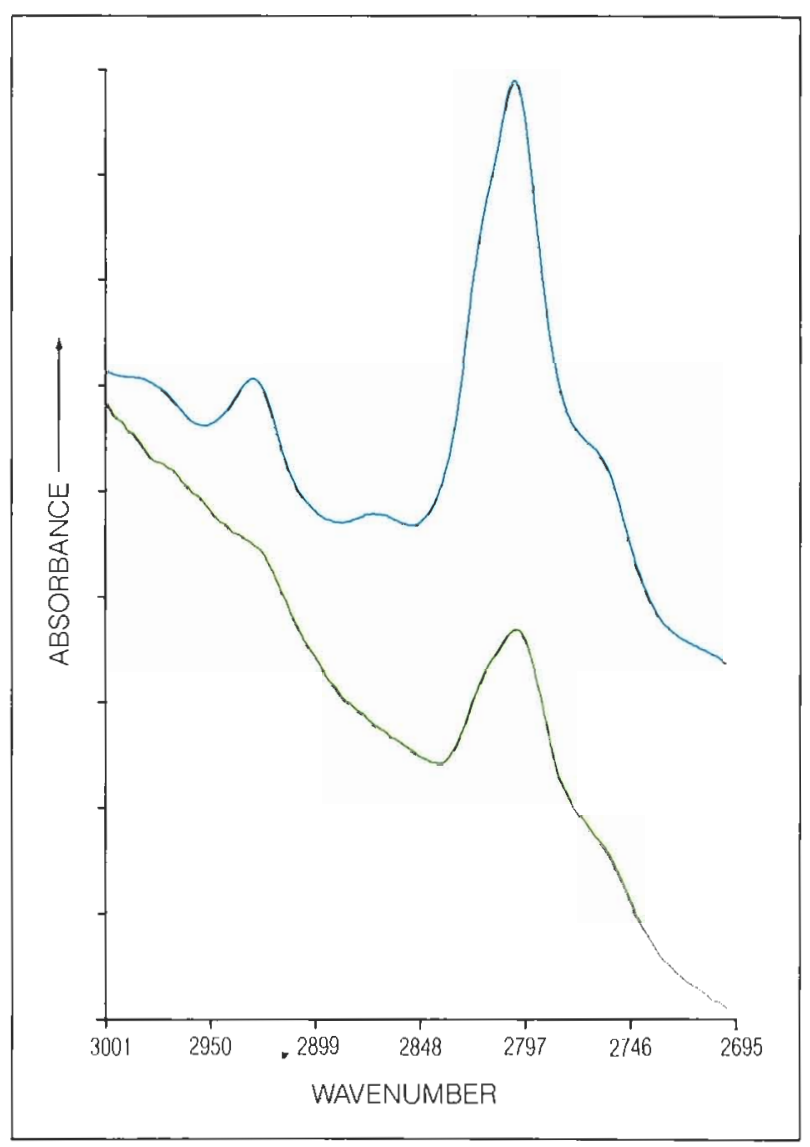

Figure 13. This portion of the infrared spectrum of a green growth sector in a greenish yellow De Beers synthetic diamond (bottom) strongly resembles that of a blue type IIb natural diamond (top), which suggests that the green sectors of this synthetic diamond have a type IIb-like character. The spectra were recorded with a Nicolet 60SX FTIR spectrometer system.

compensate for each other electrically /depending on their relative amounts), and they should not give rise to their expected yellow and blue colors simultaneously. We speculate that, in the green sectors of this synthetic diamond, these two impurities may be either dispersed as single atoms far enough apart from each other in the lattice as not to interact, or they may form a mosaic-like array of separate nitrogen- or boron-rich domains, or regions, within the diamond on an ultramicroscopic scale. Either distribution of nitrogen and boron atoms might account for the superposition of both the type Ib (yellow)- and type IIb (blue)-related features observed in the visible-range and infrared absorption spectra. This would also provide an alternative to the theory that the green color in these specimens is due to trace amounts of nickel. Absorption of violet and blue light (by nitrogen) and of orange and red light (by boron) could result 


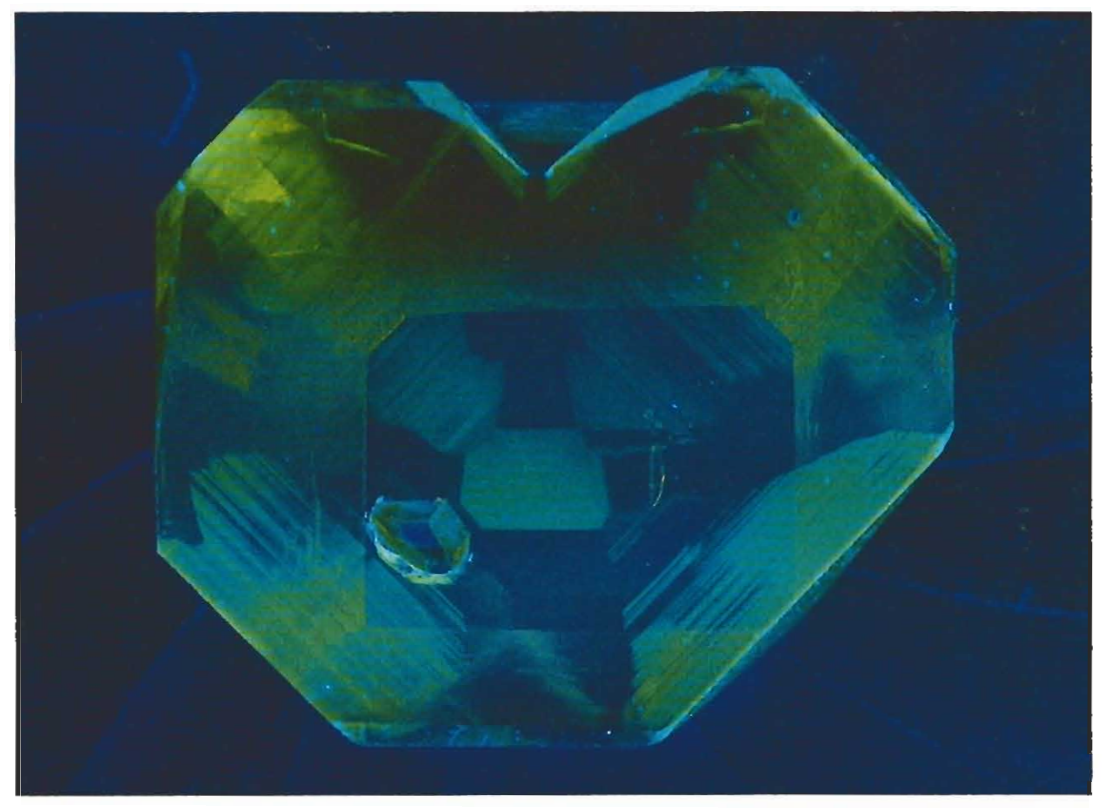

Figure 14. When this brownish yellow De Beers synthetic diamond crystal was exposed to short-wave ultraviolet radiation, the cubic growth sector in the center and the four sectors that form a "cross" pattern fuoresced intensely while the intervening octahedral sectors were inert. Parallel graining in the four outer cubic sectors was also highlighted by the fluorescence emission. The same pattern of fluorescence emission from portions of a crystal can also be seen on the crystal exterior, with the cube faces fluorescing brightly while the octahedral faces are inert. Magnified 6x; five-hour exposure.

in a diamond with a green color. Separation of dispersed boron and dispersed nitrogen atoms, or separation of type IIb domains from one another by type Ib domains, might also account for the lack of electrical conductivity in this cut stone although such conductivity is a characteristic feature of type IIb diamonds, and was observed on the surfaces of the greenish yellow crystals!

Interestingly enough, a weak, sharp absorption band at $659 \mathrm{~nm}$ was recorded at room temperature with the FTIR spectrometer in all the De Beers synthetic diamonds except the greenish yellow specimens. Collins and Spear (1982) observed a band at this location in the spectra of nickel-doped General Electric synthetic diamonds recorded at the cryogenic temperature of $77 \mathrm{~K}\left(-196^{\circ} \mathrm{C}\right)$. However, our observations of this band only in the brownish yellow and yellow De Beers synthetic diamonds suggest that any relationship between the greenish color of the greenish yellow synthetic diamonds that we examined and the presence of nickel impurities from the flux metal still seems questionable.

Ultraviolet Fluorescence. We tested the reaction of the De Beers synthetic diamonds to ultraviolet radiation at room temperature with standard U.V. lamps (Ultraviolet Products models UVG-11 and UVL-1 I). When exposed to long-wave U.V. radiation, all 14 of the De Beers synthetic diamonds are inert. In contrast, the reaction to short-wave U.V. radiation is varied. All of the brownish yellow specimens fluoresce a moderate to strong yellow or greenish yellow; the yellow synthetic diamond crystals fluoresce weak to moderate yellow, but the faceted specimens are inert; and all of the greenish yellow synthetic diamonds fluoresce a weak yellow. When the short-wave U.V. lamp is turned off, only the greenish yellow specimens phosphoresce, with a weak yellow color that lasts for 10 seconds or more (a common feature among the type IIb natural diamonds we have examined). This fluorescence and phosphorescence is most pronounced near the outer portions of the greenish yellow crystals.

In some cases, the short-wave U.V. fluorescence is emitted in a geometric zonal pattern that corresponds to the arrangement of internal sector growth described earlier; this is most pronounced in the brownish yellow crystals. As shown in figure 14, the cubic growth sectors of this crystal fluoresce intensely, while the adjacent octahedral sectors fluoresce little or not at all. Within the cubic sectors, parallel grain lines (see discussion below) are highlighted by the fluorescence emission. In addition, the fluorescence is frequently brighter near the edges between sectors. This zoned pattern of fluorescence was also observed in some of the faceted De Beers synthetic diamonds (figure 15).

This ultraviolet fluorescence behavior, particularly the response to short-wave U.V. radiation, is more varied than that observed in the Sumitomo synthetic diamonds. Thus, U.V. fluorescence may be less reliable as an identifying gemological property for synthetic diamonds of other than brownish yellow or intense yellow color. 


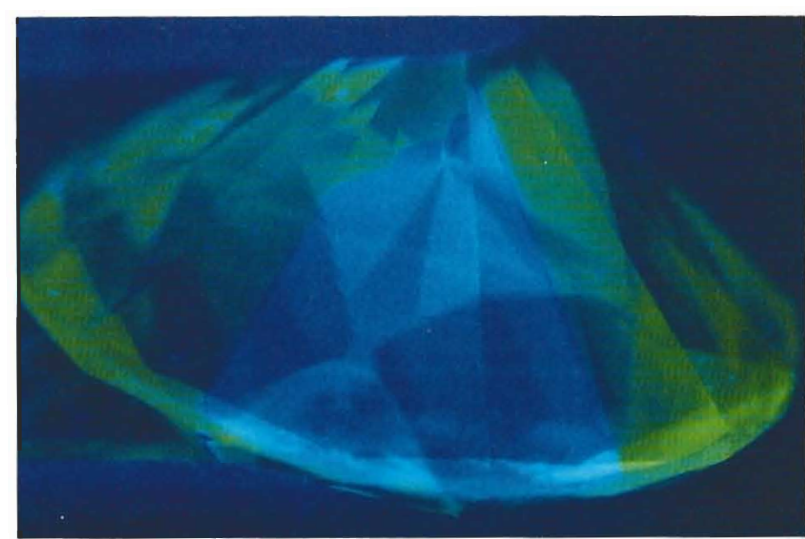

Figure 15. In faceted specimens, too, the shortwave ultraviolet fluorescence of a brownish yellow De Beers synthetic diamond shows the zoned pattern related to the internal growth sectors of the crystal. Magnified $20 \times$; four-hour exposure.

Fluorescence to X-Rays. The De Beers synthetic diamonds were tested with a conventional X-ray unit operating at $72 \mathrm{kV}$ and $13 \mathrm{~mA}$ for several seconds of exposure. The brownish yellow specimens fluoresce a dark yellow or greenish yellow of moderate intensity, again in a zonal pattern, with very slight or no phosphorescence. The yellow specimens fluoresce in a similar pattern and color but with greater intensity. Again, there is little or no phosphorescence. The greenish yellow synthetic diamonds fluoresce an even stronger yellow in a zonal pattern and, in addition, exhibit a strong phosphorescence that persists for more than 10 seconds. When tested in a similar manner, the General Electric synthetic yellow diamonds were inert while the yellow Sumitomo material fluoresced bluish white with no phosphorescence.

Cathodoluminescence. Diamonds will often luminesce when exposed to an electron beam, a characteristic referred to as cathodoluminescence. Previous studies of synthetic diamonds indicate that they can display intense and often geometrically zoned cathodoluminescence, and that this response usually differs from the pattern of cathodoluminescence observed in natural diamonds. As figure 16 illustrates, this markedly zoned luminescence can also be quite useful in investigating the internal growth sectors as well as in studying the differences in growth history of both natural and synthetic diamonds (see Kiflawi and Lang, 1974; Woods and Lang, 1975; Hanley et al., 1977).

Figure 16. In a natural diamond crystal (left), visible cathodoluminescence is exhibited by parallel zones on four sides of the crystal, where they mark successive positions of the outer edge of the diamond as it grew. Crystal growth occurred by addition of new material along planes parallel to the faces of an octahedron. Although this diamond crystal formed almost entirely by octahedral-type growth, the complicated pattern of visible luminescence is evidence of the complex growth history that is typical for many natural diamonds. In the faceted brownish yellow De Beers synthetic diamond (right), the pattern of cathodoluminescence reveals an internal structure consisting of cubic (luminescing a greenish yellow) and octahedral (inert) growth sectors. Photographs courtesy of Dr. G. S. Woods, C. S. O. Valuations, London (left) and Mrs. M. T. Rooney, D. T. C. Research Centre, Maidenhead (right).
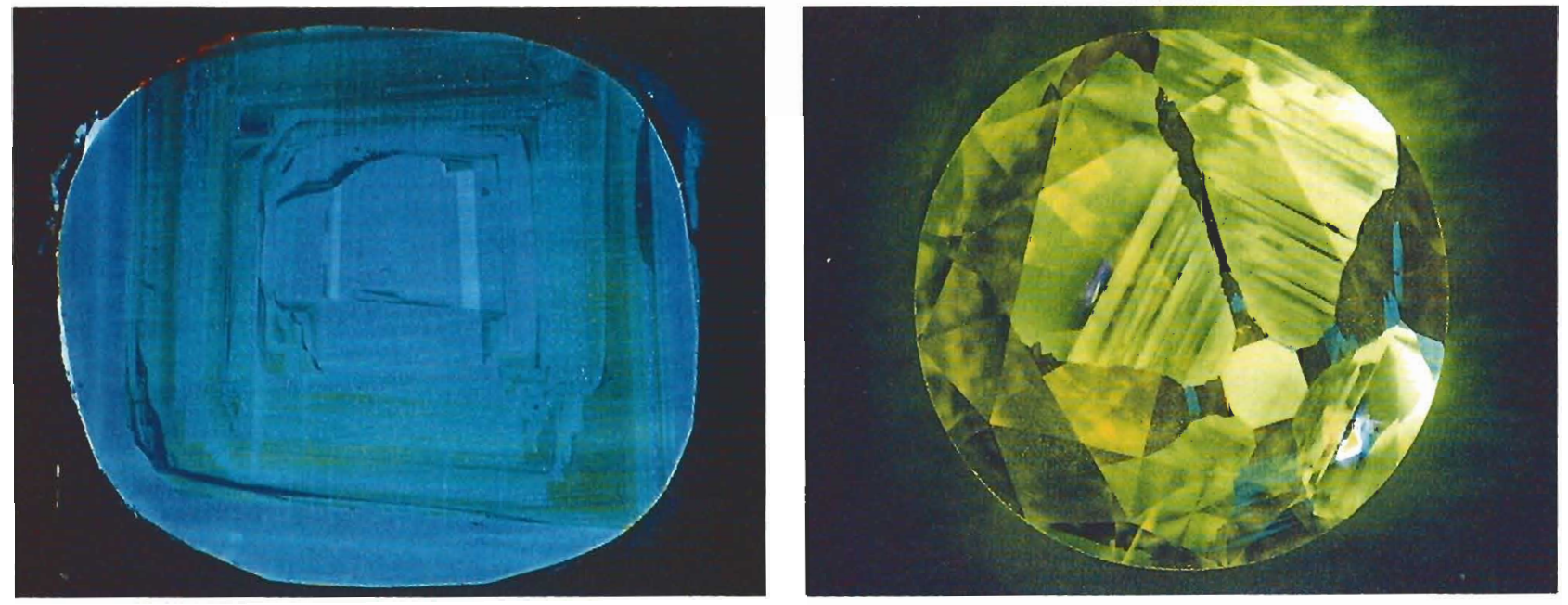
Our examination of the De Beers specimens with a Luminoscope cathodoluminescence unit revealed that the brownish yellow and yellow synthetic diamonds luminesce an orangy yellow, yellow, or greenish yellow that varies in intensity from weak to strong. The greenish yellow synthetic diamonds luminesce a weak greenish yellow. While these cathodoluminescence colors alone may not help distinguish synthetic from natural diamonds, results of the studies cited above demonstrate that observation of the zoned patterns of cathodoluminescence (as recorded, perhaps, with more sophisticated equipment) can often be significant in making this separation.

Electrical Conductivity. Each of the De Beers synthetic diamonds was tested for electrical conductivity with a gemological conductometer. All of the faceted stones are nonconductive, as are the brownish yellow and yellow crystals. However, when conductivity between two crystal faces on the greenish yellow synthetic diamonds was tested, the faces were found to be slightly conductive. Perhaps the incorporation of higher levels of impurities or defects near the outer surfaces of these crystals may explain the electrical conductivity as well as the surface ultraviolet fluorescence of the greenish yellow crystals (we have noted both features in natural type IIb diamonds).

Thermal Conductivity. When tested with a thermal conductivity meter (a GIA GEM Instruments Duotester), the De Beers synthetic diamonds (like the General Electric and Sumitomo materials) exhibit the high thermal conductivity expected for diamonds in general. Therefore, this test cannot be used to separate synthetic from natural diamonds.

Specific Gravity. The specific gravity of each of the De Beers synthetic diamonds was determined using a heavy-liquid procedure devised by Koivula and Fryer (1984). The specific gravity of these specimens was estimated to lie between 3.50 and 3.51 , which is within the range of natural and other synthetic diamonds.

Examination with the Microscope. Inclusions. Several of the De Beers synthetic diamonds of all three colors contain relatively large, dark inclusions with a metallic luster that we presume to be particles of solidified flux material. Inclusions such as these are not found in natural diamonds.
These metallic inclusions have a tabular, elongate, or needle-like shape (figure 17). The shapes result from the inclusions filling cavities in the material that show distinct crystal faces. The inclusions occur singly or in small groups, can vary in size, and are occasionally aligned in a linear or planar fashion with their long axes parallel to grain lines or to the boundaries between internal growth sectors. They can be located either near the edge or deep within a crystal, and thus are also present in the faceted specimens. In some instances, the area immediately surrounding a group of such inclusions appears slightly lighter in color for distances of several tenths of a millimeter. These inclusions seem to be larger in the greenish yellow specimens.

Tiny, white-appearing "pinpoints" were also observed. They, too, are often arranged in a pattern along grain lines or growth sector boundaries (figure 18). In some of the faceted specimens, these pinpoint inclusions occur in such abundance that they assume a cloud-like form that imparts a haziness to the stone (figure 19).

Color Zoning. Also interesting are the narrow, near-colorless, vein-like areas (figure 20) that extend inward from the edge of a crystal, usually just beneath a cube or dodecahedral face. When these areas are clearly visible, their location is seen to correspond to that of the cubic growth sectors discussed earlier. The variation in color between the vein-like areas and adjacent growth sectors is

Figure 17. Large metallic inclusions, presumably particles of solidified flux filling cavities in the host stone, were observed in several of the De Beers synthetic diamonds. Magnified 25x.

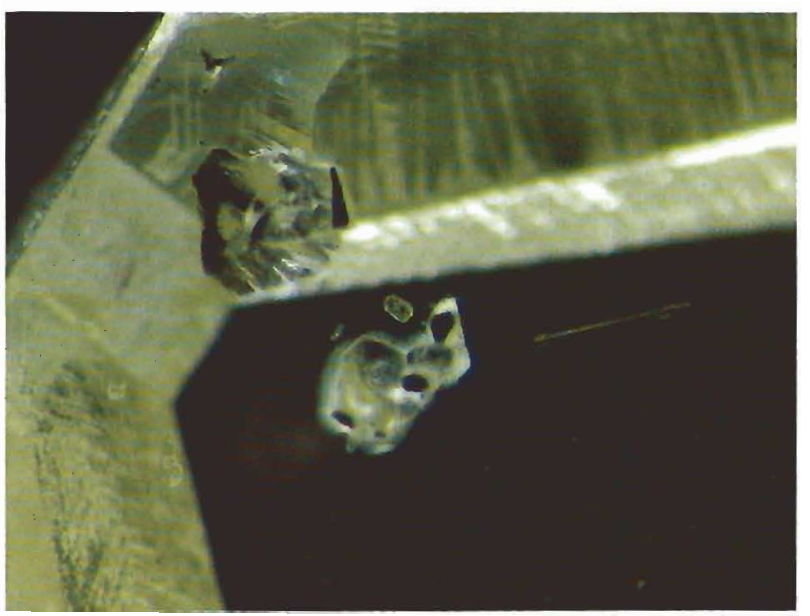




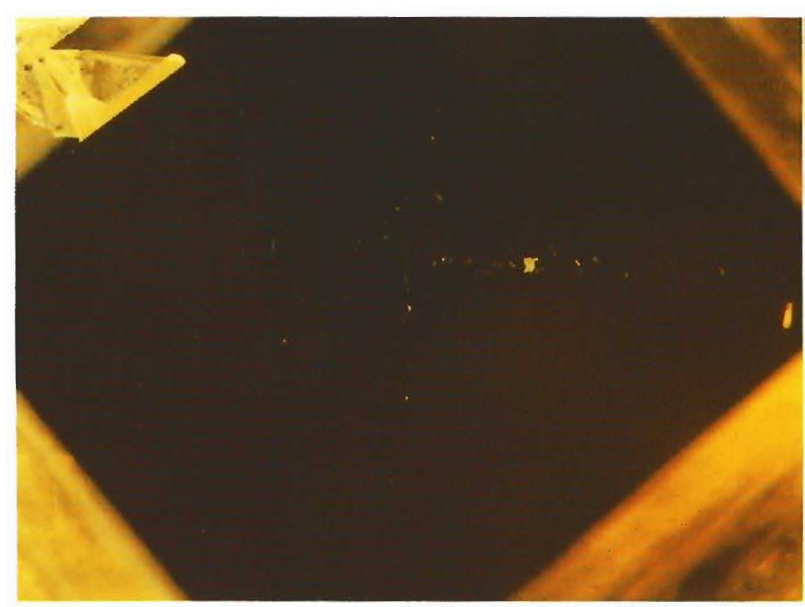

Figure 18. Tiny pinpoint inclusions arrayed in the form of a "cross" in the center of this yellow De Beers synthetic diamond crystal mark the boundaries between internal growth sectors. Magnified $20 \times$.

likely to be related to the differences in nitrogen incorporation among sectors during crystal growth. Near-colorless, vein-like areas of similar appearance' were also prominent in the yellow Sumitomo synthetic diamonds.

Graining. Many of the De Beers synthetic diamonds also exhibit a distinct pattern of grain lines that are seen internally and sometimes on the surface. Before we describe this feature, however, some remarks about the meaning of the term graining may help clarify our observations.

Graining is a general term used by gemologists to describe irregular, linear, or planar growth features visible either internally or on the surface of a diamond. When there is surface graining, it usually can be correlated with internal graining. Although graining seems to be a relatively common feature in gem diamonds, and may be an important factor in the quality grading of otherwise flawless stones, little has been written on the subject except for the articles by Kane (1980, 1982).

Internal graining has been ascribed to differences in lattice orientation, the presence of inclusions, or other structural irregularities in the diamond (Kane, 1982). Its occurrence often seems to be associated with optical birefringence, which might in turn be related to strain. Some internal graining has been correlated with twinning in diamond (J-P. Poirot, pers. comm., 1987). However, most internal graining occurs in untwinned diamond crystals. While there is probably some rela-

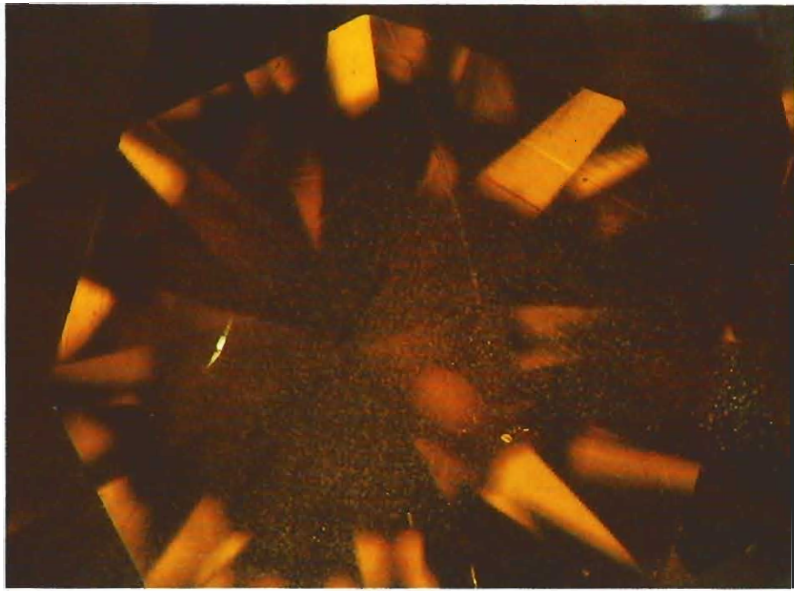

Figure 19. In some of the faceted De Beers synthetic diamonds, numerous tiny pinpoint inclusions form a "cloud" that gives a hazy appearance to the stone. Magnified $20 \times$.

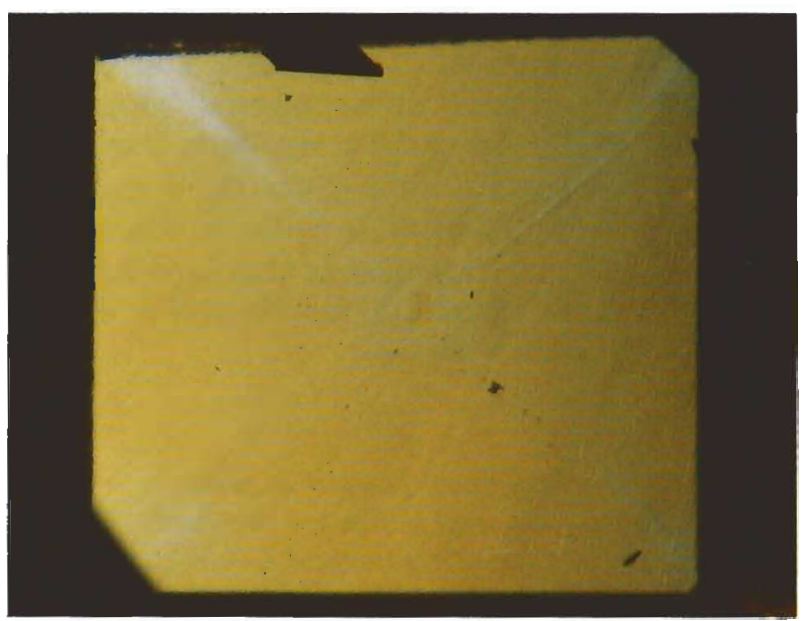

Figure 20. The narrow, near-colorless, vein-like areas that extend inward from the four corners of this yellow De Beers synthetic diamond crystal correspond to the cubic growth sectors. These near-colorless areas may not be as well developed or as obvious in a faceted stone, but they are commonly seen and are quite distinctive of this material. Magnified $20 \times$.

tionship between internal graining and features such as irregularities in crystal structure, we suggest that much internal graining is due to a slight difference in refractive index between neighboring regions of the diamond that gives rise to an optical contrast between the two regions. A difference in refractive index is brought about by minor variations in composition and/or structure. In the 
case of the synthetic diamonds we examined, these differences are most likely associated with variations in nitrogen content.

Internal graining in natural diamonds usually parallels the four possible octahedral planes in the crystal. As such, it provides a phantom temporal record of the crystal shape during earlier stages of crystal growth. In the De Beers synthetic diamonds, however, most of the internal graining is parallel to cube faces, and is best developed in the cubic growth sectors (but it is absent in the neighboring octahedral sectors - again, see figure I0). This may be the result of more rapid grow th in the cubic sectors, which leads to a greater probability of compositional differences and structural irregularities land thus to differences in refractive index) in these sectors.

Some graining marks the boundaries between growth sectors where interfacing of compositional or structural differences can also lead to refractiveindex variations. Both the boundary- and the cubic sector-related internal graining give rise to the distinctive "hourglass" and octagonal "stopsign" patterns seen in some of these synthetic diamonds (figures 21 and 22). Similar patterns of graining were noted in the Sumitomo synthetic diamonds. Internal and surface graining of this kind has not been reported in natural diamonds, and is thus a key identification criterion.

Figure 21. The "hourglass" pattern as seen through the pavilion of this faceted brownish yellow De Beers synthetic diamond results from the development of prominent internal graining; it is a characteristic feature of many large synthetic diamonds.

Magnified $30 \times$.

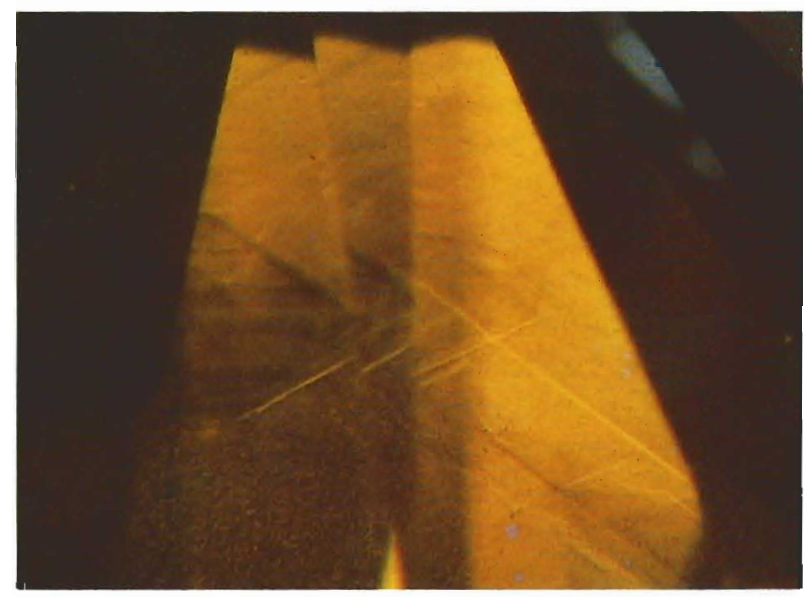

Appearance in Polarized Light. Natural diamonds exhibit linear, cross-hatched, mosaic, or inclusionrelated strain patterns when observed in polarized light. In contrast, the De Beers synthetic diamonds have a distinct cross-shaped strain pattern (figure 23). Typically, this pattern is centered at the midpoint of the crystal. In a faceted synthetic diamond, the strain pattern is aligned along the same directions as the internal graining, and thus can be an aid in examining a stone for the "hourglass" graining pattern. Some strain may also be associated with large inclusions in this material.

Chemical Analysis of Inclusions. Using a Cameca MBX electron microprobe, Paul Hlava investigated the chemical composition of the large metallic inclusions exposed at the surfaces of one of the yellow and one of the greenish yellow synthetic diamonds. Because of the irregular surfaces of the inclusions, fully quantitative results could not be obtained. However, X-ray mapping of the inclusions in the two synthetic diamonds showed them to be metal alloys that are similar in composition, with close to $60 \mathrm{wt} . \%$ iron and $40 \mathrm{wt} \%$ nickel, which is a common composition for the flux material used in diamond crystal synthesis see

Figure 22. An octagonal "stopsign" pattern of surface graining is also visible on the polished table of the synthetic diamond shown in figure 21. Near the lower right-hand edge of the table, the central cubic-sector core of the crystal is recognizable from its octagon-shaped outline. Four narrow octahedral growth sectors extend outward from the core at right angles to one another. Also visible are the four cubic growth sectors with their parallel surface grain lines. Oblique illumination; magnified $30 \times$.

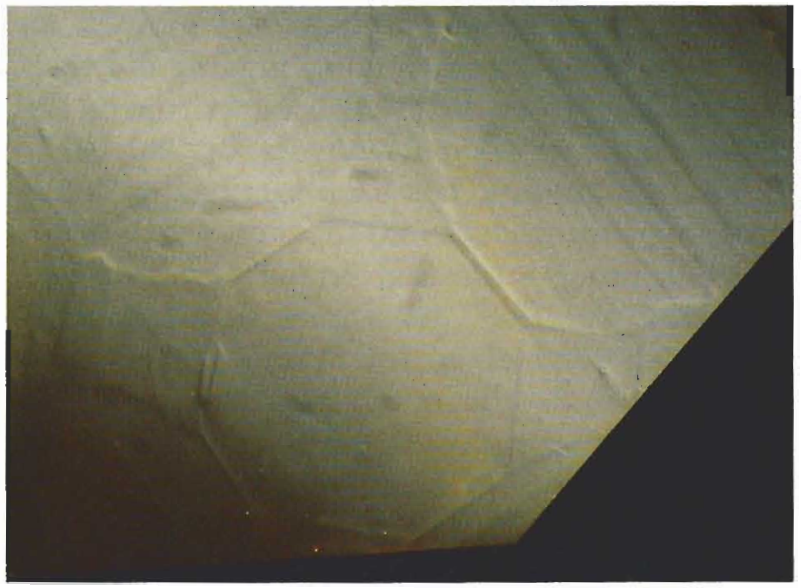


Bundy et al., 1973). Inclusions of metal alloys are not found in natural diamonds. Mr. Hlava also noted in the yellow specimen that there are numerous, scattered, 1-2 $\mu \mathrm{m}$ inclusions in which only iron was detected. The arrangement of these tiny inclusions observed with the microprobe corresponds to the visual pattern of white-appearing pinpoints mentioned earlier. Again, although pinpoint inclusions are seen in natural diamonds, they do not look like those we observed in the De Beers synthetic diamonds.

Magnetic Behavior. The presence of obvious magnetic behavior in synthetic diamonds was noted in the General Electric material by B. W. Anderson (Webster, 1970) and Koivula and Fryer (1984), and was subsequently observed in the Sumitomo synthetic diamonds by Shigley et al. (1986). Natural diamonds are only weakly magnetic if at all (Rossman and Kirschvink, 1984). Because of the presence of large metallic inclusions (believed to be remnants of flux material on the basis of their appearance and chemistry), we suspected that the De Beers synthetic diamonds might be attracted by a magnet: During the specific-gravity determination, we tested this by placing a simple horseshoe magnet next to the glass container that held the synthetic diamonds suspended in the heavy liquid. The magnetic response could then be roughly gauged by the relative movement of the suspended sample toward the magnet. We found the De Beers synthetic diamonds to vary from strongly magnetic to nonmagnetic. The larger the metallic inclusions are, the stronger the attraction of the synthetic diamond is to the magnet. We noted no relationship between magnetic behavior and the color of the synthetic diamonds except insofar as the greenish yellow specimens are more strongly magnetic because, generally speaking, they contain the larger metallic inclusions.

\section{CONCLUSION}

Although large, colored synthetic diamonds in a size and quality suitable for faceting have been produced at the De Beers Diamond Research Laboratory since the 1970s, this is the first gemological examination of this material. These large synthetic diamonds have been manufactured only for scientific study and are not yet commercially available. They have not been introduced into the jewelry market, and De Beers maintains that there are no plans to do so. However, the cooperation of

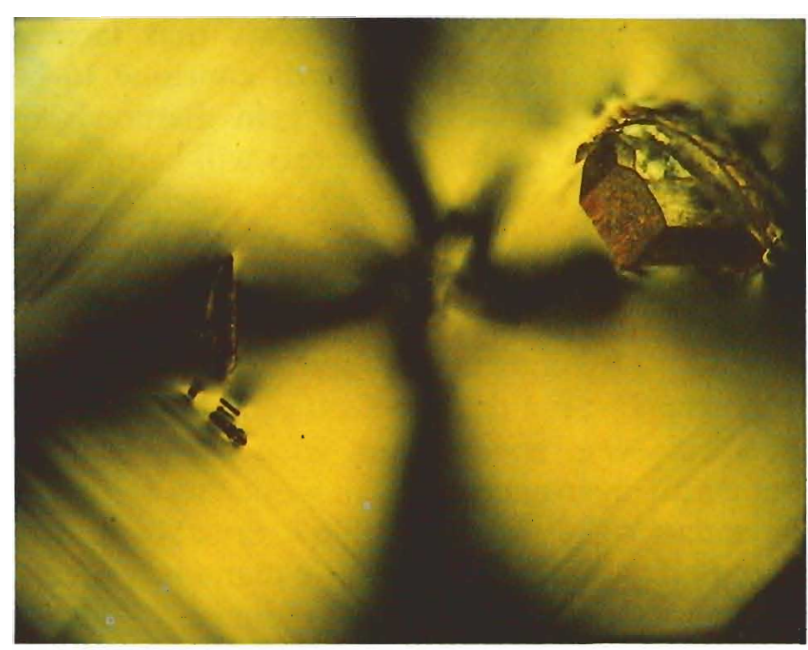

Figure 23. This cross-shaped internal strain pattern, here seen in a crystal, is distinctive of many of the De Beers synthetic diamonds. Note also the pattern of graining in the four cubic sectors. Cross polarized light; magnified $10 \times$.

De Beers representatives in providing synthetic diamonds as well as information on their diamond synthesis technology has enabled us to report on the gemological properties of this material.

The De Beers gem-quality synthetic diamonds can be easily identified in cut form by means of conventional gemological testing techniques. Table 2 summarizes the distinctive properties of the faceted specimens. Features to look for are the distinctive zoned pattern of color, ultraviolet fluorescence, and internal graining, as well as the metallic inclusions. While some of these properties are unique to synthetic diamonds (i.e., certain patterns of internal and surface graining, metallic inclusions|, others may resemble those of natural gem diamonds (i.e., color zonation, pinpoint inclusions). Thus, determination of natural or synthetic origin should not be based on any one gemological property alone. In combination, however, the characteristic gemological properties of these gemquality synthetic diamonds provide conclusive identification.

With the exception of ultraviolet fluorescence, the gemological properties of the De Beers synthetic diamonds are consistent with those noted previously for the General Electric and Sumitomo gem-quality synthetic diamonds of comparable colors. We have now examined samples of gemquality synthetic diamonds from three different sources (two of which represent current technology), and have found them to be easily recognizable 
by the gemologist. This suggests that faceted yellow synthetic diamonds will continue to be distinguishable from natural gem diamonds of similar color. Whether or not this will be the case for other colors of gem-quality synthetic diamonds, if and when they are consistently produced, remains to be seen. Among the synthetic diamonds we have examined so far, the most distinctive gemological properties (such as color zoning) present in the brownish yellow and yellow material seem to correlate with the relatively higher nitrogen content. Such properties were less obvious in the greenish yellow crystals. In the future, if gem-quality synthetic diamonds with a lower nitrogen content are produced, as is expected for colorless stones, these distinctive gemological properties may be less evident or even absent. On the basis of our observations to date, we foresee difficulties in separating natural from synthet ic colorless diamonds using convent ional gemological techniques.

The fact that De Beers and Sumitomo have independently developed the commercially feasible technology to synthesize yellow gem-quality diamonds as large as several carats reinforces our view that in the future synthetic diamonds will be encountered more frequently in the jewelry industry. We have now entered into a new era of commercial diamond synthesis technology. We again recommend that jewelers and gemologists pay close attention to documenting the gemological properties of gem diamonds of yellow color.

\section{REFERENCES}

Bovenkerk H.P. (1960) Some observations on the morphology and physical characteristics of synthetic diamond. In F. P. Bundy, W. R. Hibbard Jr., and H. M. Strong, Eds, Progress in Very High Pressure Research, John Wiley \& Sons, New York, pp. 58-69.

Bundy F.P., Hall H.T., Strong H.M., Wentorf R.H. Jr. (1955) Manmade diamond. Nature, Vol. 176, pp. 51-54.

Bundy F.P., Strong H.M., Wentorf R.H. Jr. (1973) Methods and mechanisms of synthetic diamond growth. Chemistry and Physics of Carbon, Vol. 10, pp. 213-263.

Chrenko R.M., Strong H.M., Tuft R.E. (1971) Dispersed paramagnetic nitrogen content of large laboratory diamonds. Philosophical Magazine, Series 8, Vol. 23, pp. 313-318.

Clark C.D., Mitchell E.W.J., Parsons B.J. (1979) Colour centers and optical properties. In J. E. Field, Ed., The Properties of Diamond, Academic Press, London, pp. 23-77.

Collins A.T., Spear P.M. (1982) Optically active nickel in synthetic diamond. Journal of Physics D, Applied Physics, Vol, 15, pp. L183-L187.

Crowningshield R. \{1971) General Electric's cuttable synthetic diamonds. Gems \& Gemology, Vol. 13, No. 10, pp. 302-314.
Fryer C.W., Crowningshield R., Hurwit K.N., Kane R.E. (1987) Gem trade lab notes - Synthetic diamond. Gems \& Gemology, Vol. 23, No. 1, p. 44.

Hanley P.L., Kiflawi l., Lang A.R. (1977) On topographically identifiable sources of cathodoluminescence in natural diamonds. Philosophical Transactions, Vol. A284, pp. 329-368.

Kane R.E. (1980) The elusive nature of graining in gem-quality diamonds. Gems e) Gemology, Vol. 16, No.9, pp. 294-314

Kane R.E. (1982) Graining in diamond. In D. M. Eash, Ed., International Gemological Symposium Proceedings 1982, Gemological Institute of America, Santa Monica, CA, pp. 219-235.

Kiflawi I., Lang A.R. (1974) Linearly polarized luminescence from linear defects in natural and synthetic diamond. Philosophical Magazine, Series 8, Vol. 30, pp. 219-223.

Koivula J.I., Fryer C.W. (1984) Identifying gem-quality synthetic diamonds: an update. Gems e) Gemology, Vol. 20, No. 3, pp. $146-158$.

Lang A.R. (1979) Internal structure. In J. E. Field, Ed, The Properties of Diamond, Academic Press, London, pp. $425-469$.

Moore A.M. (1979) Optical studies of diamonds and their surfaces: a review of the late Professor Tolansky's work. In J. E. Field, Ed., The Properties of Diamond, Acadenic Press, London, pp. 245-277.

Muncke G. (1979) Physics of diamond growth. In J. E. Field, Ed., The Properties of Diamond, Academic Press, London, pp. 425-469.

Orlov Y.L. ( I 977) The Mineralogy of the Diamond, John Wiley \& Sons, New York.

Patel A.R., Ramachandran N. (1968) Growth hillocks on (100) faces of synthetic diamond. Journal of Physics and Chemistry of Solids, Vol. 29, pp. 190-192.

Patel A.R., Ramanathan S. (1963) Triangular pyramids on the octahedral faces of synthetic diamonds. Physica, Vol. 29, pp. 889-895

Rossman G., Kirschvink J.L. (1984) Magnetic properties of gemquality synthetic dianonds. Gems es) Gemology, Vol. 20 No. 3, pp. 163-166.

Shigley J.E., Fritsch E., Stockton C.M., Koivula J.I., Fryer C.W., Kane R.E. (1986) The gemological properties of the Sumitomo gem-quality synthetic yellow diamonds. Gems e) Gemology, Vol. 22, No. 4, pp. 192-208.

Strong H.M., Chrenko R.M. (1971) Further studies on diamond growth rates and physical properties of laboratory-made diamonds. Journal of Physical Chemistry, Vol. 75 , No. 12, pp. $1838-1843$.

Strong H.M., Wentorf R.H. Jr. (1972) The growth of large synthetic diamond crystals. Die Naturwissenschaften, Vol. 59, No. 1, pp. 1-7.

Tolansky S. (1961) Comparative optical and interferometric studies on synthetic diamonds. Proceedings, Royal Society of London, Vol. A263, pp. 3I-38.

Tolansky S. (1962) Synthetic dianonds: growth and etch phenomena. Proceedings, Royal Society of London, Vol. A270, pp. 443-451.

Tolansky S., Sunagawa 1. (1959) Spiral and other growth forms of synthetic diamonds: a distinction between natural and synthetic diamonds. Nature, Vol. 184, No. 4698, pp. $1526-1527$.

Webster R. (1970) Gems, Their Sources, Descriptions, and Identification, 2nd ed. Butterworths, London.

Wedlake R.J. (1979) Technology of diamond growth. In J. E. Field, Ed., The Properties of Diamond, Academic Press, London, pp. 501-535.

Woods G.S., Lang A.R. (1975) Cathodoluminescence, optical absorption and X-ray topographic studies of synthetic diamonds. Journal of Crystal Growth, Vol. 28, pp. 215-226. 